\title{
Optimization of hyphenated asymmetric flow field-flow fractionation for the analysis of silver nanoparticles in aqueous solutions
}

\author{
Felix Geißler $^{1} \cdot$ María Martínez-Cabanas $^{1}$ - Pablo Lodeiro ${ }^{1,2}$ • Eric P. Achterberg ${ }^{1}$
}

Received: 27 April 2021 / Revised: 6 August 2021 / Accepted: 2 September 2021 / Published online: 19 September 2021

(C) The Author(s) 2021

\begin{abstract}
The extensive use of silver nanoparticles (AgNPs) in consumer products, medicine, and industry leads to their release into the environment. Thus, a characterization of the concentration, size, fate, and toxicity of AgNPs under environmental conditions is required. In this study, we present the characterization and optimization of an asymmetric flow field-flow fractionation (AF4) system coupled with UV/Vis spectrophotometer and dynamic light scattering (DLS) detector as a powerful tool for the size separation and multi-parameter characterization of AgNPs in complex matrices. The hyphenated AF4-UV/Vis-DLS system was first characterized using individual injections of the different size fractions. We used electrostatically stabilized AgNPs of 20-, 50-, and 80-nm nominal diameters coated with lipoic acid. We investigated the effect of applied cross-flows, carrier solutions, focus times, and quantity of injected particles on the nature of the AF4 fractograms and on the integrity of the AgNPs. Best size separation of a 1:1 mixture of 20- and 80-nm AgNPs was achieved using cross-flows of 0.5 and $0.7 \mathrm{~mL} / \mathrm{min}$ with $1 \mathrm{mM} \mathrm{NaCl}$ and $0.05 \% \mathrm{v} / \mathrm{v}$ Mucasol as carrier solutions. We also researched the behavior of AgNPs in natural waters using the hyphenated AF4UV/Vis-DLS system, under determined optimal conditions.
\end{abstract}

Keywords AgNP $\cdot$ Marine waters $\cdot \mathrm{AF} 4 \cdot$ Aggregation

\section{Introduction}

Nanoparticles are materials with nanometric size, typically below $100 \mathrm{~nm}$. The small size of the nanoparticles, together with their large surface to volume ratio, leads to distinctive properties that make them different from the bulk material [1].

Silver nanoparticles (AgNPs) are one of the most widely used nanoparticles, with a large range of applications [2]. The unique optical properties of the AgNPs are well known and make them useful for biosensing and imaging applications [3-5]. The AgNPs can also be used in catalyzed reactions [6-8] and electronic applications [9-11]. Nevertheless, the most common and widely utilized properties of AgNPs are

María Martínez-Cabanas

mmartinez@geomar.de

1 Chemical Oceanography, Marine Biogeochemistry, GEOMAR Helmholtz Centre for Ocean Research Kiel, Kiel, Germany

2 Department of Chemistry, University of Lleida AGROTECNIO-CERCA Center, Rovira Roure 191, 25198 Lleida, Spain their antibacterial, antiviral, and biocidal abilities. These properties make AgNPs to be widely used in medical products, disinfectants, and food packing materials cosmetics [12], and as antiviral agents and drug delivery carriers for several human diseases like HIV-1, hepatitis, and even COVID-19 [13, 14]. The extensive production and consumption of AgNPs inevitably lead to increased exposure for humans and ecosystems. The AgNPs enter ecological systems as a consequence of leaching and recycling processes, through discharge in wastewater or atmospheric deposition $[15,16]$. The European Union has reported that AgNPs are the second most abundant nanoparticles in surface waters with average concentrations around $1.5 \mathrm{ng} \cdot \mathrm{L}^{-1}$ [1]. Very few studies were able to measure AgNPs in natural waters, with concentration levels depending on the studied locations. For example, AgNP levels between 2.0 and $8.6 \mathrm{ng} \mathrm{L}^{-1}$ were found in the river Isar (Germany) [17], while a recent study in Besós river basin (Spain) showed an average value of $640 \mathrm{pg} \mathrm{L}^{-1}$, one order of magnitude lower [18].

The AgNPs' behavior and fate largely depend on their specific properties (e.g., capping agent, surface charge, particle diameter) and the characteristics of the surrounding medium 
(e.g., electrolyte composition, $\mathrm{pH}$, ionic strength, presence of organic matter) $[1,19,20]$. Thus, the research of both the pristine NP characteristics and their modifications due to specific medium parameters is key to constrain potential toxic effects $[21,22]$. In order to stablish the fate and toxicity of the AgNPs in the environment, it is therefore essential to develop methods and techniques to study their stability, distribution, and transport [16].

Field-flow fractionation (FFF) is one of the techniques with a higher potential to evaluate the behavior of the nanoparticles in aquatic environments. The FFF is a versatile fractionation method which allows the analytical separation and characterization of molecules and particles in a large range of sizes (from $\mathrm{nm}$ to $\mu \mathrm{m}$ ) [23]. The FFF separation takes places in a thin ribbon-like channel and is based on the combination of the action of a carrier solution with a hyperbolic velocity profile, together with a physical field applied perpendicularly to this carrier liquid. Thus, the sample is carried downstream at different velocities and eluted from the channel with different retention times $[24,25]$. In the last decades, multiple variations of FFF have been developed based on the type of separation force. The most versatile is the flow field-flow fractionation (FlFFF) that can be applied to compounds in the size range from $20 \mathrm{~nm}$ to $100 \mu \mathrm{m}$. This sub-technique uses a secondary flow (cross-flow) as field force. By the application of the cross-flow, the analytes are driven towards the channel's permeable membrane, and the fractionation is achieved due to different diffusion coefficients. The FIFFF has mainly two possible setups: the symmetric FlFFF, where two independent flows are applied; and the asymmetric FlFFF or AF4, where the two flows (longitudinal and cross-flow) are produced by the same inlet [26]. The efficiency of the FlFFF technique in terms of size detection and quantification of manufactured AgNPs was evaluated by Cascio et al. [27], among other well-established methods, such as centrifugal liquid sedimentation or transmission electron microscopy (TEM) analyses.

Despite its multiple advantages, the use of FFF as a sorting tool for engineered nanoparticles in industrial processes is limited due to the inability to scale up the process. The implementation of new separation techniques like the zonal rotor centrifugation, based on the creation of density gradients [28], or the magnetic bearing-based high-speed centrifugation [29] opens the possibility to carry out the separation of differentsized nanoparticles in large-scale systems. Despite the promising results of these methods for the high-resolution separation of nanoparticle samples, there is a lack of information on their capability to be hyphenated to other instruments (like DLS, ICP, or UV/Vis), an essential feature to make easier the characterization of the separated fraction sizes.

The hyphenation of the non-destructive FFF system with various detectors is the main powerful advantage for the characterization of nanoparticle-containing samples. A method to achieve multidimensional information (e.g., hyphenated techniques) is highly desirable for the analysis of environmental samples, which is normally challenging due to complex sample matrices and low nanoparticle concentrations [30]. A number of studies have successfully evaluated the on-line hyphenation of the FIFFF to several detectors such as UV/Vis, fluorescence, ICP-MS, or dynamic light scattering (DLS) [31-36]. Marassi and co-workers demonstrated the viability of hollow-fiber flow field-flow fractionation hyphenated with multi-angle light scattering for the characterization of AgNPs in both pharmaceutical and medical products, and aqueous environments [37-39]. The FlFFF was successfully used to evaluate the size distribution in soils and water of natural colloids (like humic and fulvic acids) and their association to trace metals [40-44]. The effect of organic matter on the size and surface of PtNPs in artificial and natural waters was recently studied by Sánchez-Cachero and co-workers using AF4 hyphenated with ICP-MS [32]. The viability of AF4 for the separation and size characterization of $\mathrm{ZnO}$ nanoparticles in river and lake water was confirmed by Amde et al. [45]. Regarding the AgNPs, the use of FlFFF for their fractionation and characterization in freshwaters was reported by several authors. Kim and co-workers probed the efficiency of AF4 coupled with a liquid capillary cell for the size determination of natural AgNPs in groundwater [46]. Loosli et al. used a AF4-ICP-MS system for the characterization of natural and engineered AgNPs extracted from river waters $[47,48]$. The characterization of AgNPs in river and lake waters by AF4 demonstrated the effect of natural organic matter on the stabilization of the nanoparticles [49]. Other studies showed the promising capacity of AF4 as a tool for analyzing the persistence and transformation of AgNPs in littoral lake mesocosms and wastewaters [50, 51]. More recently, Boughbina-Portolés et al. analyzed the stability of AgNPs in different water matrices by using an AF4-UV/VIS-DLS system [52]. Nevertheless, there is still a lack of FlFFF studies in marine and estuarine water samples, in terms of characterization, quantification, and stability of AgNPs derived from natural and anthropogenic sources, and more specifically the optimization of the selected AF4 parameters for AgNP separation in complex matrices.

In this work, an AF4 system was hyphenated with the UV/ Vis and DLS detectors to characterize and investigate the behavior of AgNPs of 20, 50, and $80 \mathrm{~nm}$ coated with lipoic acid. The AgNP concentrations used in this study are in the order of milligrams per liter. The aggregation and dissolution of NPs are influenced by their concentration in solution; thus, caution is advised when extrapolating the results to very low AgNP concentrations $(\mathrm{ng} / \mathrm{L})$ of environmental relevance. Our aims were to investigate the effect of applied cross-flows, carrier solutions, focus times, and quantity of injected particles on the nature of the $\mathrm{AF} 4$ fractograms, recoveries, and on the behavior of the AgNPs. We also report the results of a case study assessing the aggregation of AgNPs in natural fjord waters 
under previously optimized AF4 conditions. Overall, we consider the provided information novel and relevant for the optimization of AF4 separation techniques with NPs.

Our final goal is to stablish a method for the characterization of the stability, size distribution, transport, and concentration of AgNPs in high ionic strength matrices such as estuarine and marine waters.

\section{Materials and methods}

Spherically shaped AgNPs coated with lipoic acid (AgNP_LA) were purchased from nanoComposix (Prague, Czech Republic) in three different nominal sizes given by the supplier $(20,50$, and $80 \mathrm{~nm}$ in diameter) as $1 \mathrm{~g} / \mathrm{L}$ dispersions (BioPure ${ }^{\mathrm{TM}}$ ) in ultrapure water. These stock dispersions were diluted with ultrapure water obtained from a Milli-Q water purification system (Merck group), with a resistivity of $18.2 \mathrm{M} \Omega \cdot \mathrm{cm}$ and total organic carbon of $<5 \mathrm{ppb}$, to 10 and $50 \mathrm{mg} / \mathrm{L}$ working dispersions. These working solutions were kept refrigerated at $5{ }^{\circ} \mathrm{C}$ in polypropylene vials covered from light. Before use, the working dispersions were treated for $2 \mathrm{~min}$ in an ultrasonic bath in order to eliminate any agglomerates.

The AF4 separation system used in this study is shown in the graphical abstract. Carrier and cleaning solutions were supplied to the separation system via a Dionex ICS-900 pump (Thermo Fisher Scientific, USA). The isocratic pump comprised a 6-way valve for fluidic control and an injection loop (Rheodyne) which was manually loaded with AgNP working dispersions using a syringe. Loops with an internal volume of 20 and $100 \mu \mathrm{L}$ were used for the injection of 50 and $10 \mathrm{mg} / \mathrm{L}$ AgNP dispersions, respectively, equal to the injection of $1.0 \mu \mathrm{g}$ of AgNPs. An Eclipse AF4 system (Wyatt Technology Europe GmbH, Germany) regulated all programmed steps of the separation including applied flow profiles, rates, directions, durations, and pressures. The Dionex pump and the Eclipse AF4 system were controlled via the software Chromeleon (version 6.80 SR13, Thermo Fisher Scientific, USA). Fluidic connection between pump and Eclipse AF4 and between Eclipse AF4 and separation channel was facilitated via polyether ether ketone (PEEK) tubing with inner diameters of 0.5 and $0.25 \mathrm{~mm}$, respectively. The length of the separation channel was $29 \mathrm{~cm}$ with a height of $350 \mu \mathrm{m}$, defined by the dimensions of the used trapezoidal-shaped PEEK spacer. The separation membrane (Wyatt Technology Europe GmbH, Germany) was located between spacer and bottom ceramic frit and was made of polyether sulfone (PES) with a cutoff of $10 \mathrm{kDa}$. The membranes were replaced after ca. 50 consecutive runs. After replacement, at least five runs were performed in order to condition the new membrane with AgNPs. Silver nanoparticles were introduced from the injection loop onto the separation membrane using a flow rate of $0.2 \mathrm{~mL} / \mathrm{min}$. A flow rate of $0.5 \mathrm{~mL} / \mathrm{min}$ was chosen for the detector and the channel. The separation protocol comprised six consecutive steps, each characterized by its individual duration and applied cross-flow rate $\left(V_{x}\right)$ as shown in the example of Table S1.

For the evaluation of the quality of the separation and the characterization of the AgNP fractions' optical properties, $\mathrm{UV} / \mathrm{V}$ is spectra were recorded using a Shimadzu SPDM10Avp photodiode array detector (PDA, graphical abstract) linked to the Eclipse AF4 device with 0.25-mm ID PEEK tubing and controlled with a SCL-10Avp unit via the LCsolution software 1.03 SP3 (Shimadzu). UV/Vis spectra were analyzed at the respective absorption maximum $\left(\lambda_{\max }\right)$ of the individual AgNP size fractions, with $\lambda_{\max }(d=20 \mathrm{~nm})$ $=399 \mathrm{~nm}, \lambda_{\max }(d=50 \mathrm{~nm})=422 \mathrm{~nm}$, and $\lambda_{\max }(d=80 \mathrm{~nm})$ $=469 \mathrm{~nm}$. Fractograms of a 1:1 mixture of 20- and 50-nm as well as 20- and 80-nm AgNPs were analyzed at wavelengths of 410 and $434 \mathrm{~nm}$, respectively (average wavelength of the individual absorption maxima). For a characterization of the AgNP fractions in terms of particle size via dynamic light scattering (DLS), a ZetaSizer Nano-ZS (Malvern, UK; DLS (8) in graphical abstract) was linked to the Eclipse AF4 device with $0.25-\mathrm{mm}$ ID PEEK tubing. The particle size was determined every $3 \mathrm{~s}$ using a quartz flow-through cell ZMV1008 (Hellma Analytics, Germany; $3 \times 3 \mathrm{~mm}, 8.5$-mm center height). In order to provide sufficient backpressure for the system (ca. 13 bar was required with a detector flow rate of $1 \mathrm{~mL} / \mathrm{min}$ and no applied cross-flow according to the Eclipse AF4 handbook), the length of a 0.125 -mm ID PEEK tubing at the sample outlet towards the waste was adjusted accordingly.

Three different carrier solutions were used for the AF4 experiments:

1. $\mathrm{pH}$-adjusted ultrapure water $(\mathrm{pH}=8, \mathrm{I}=0.02 \mathrm{mM})$; from now on "water $\mathrm{pH} 8$ "

2. Sodium chloride $1 \mathrm{mM}(\mathrm{NaCl}$, reagent grade; Fisher Chemicals, UK) in ultrapure water $(\mathrm{pH}=8)$

3. Mucasol® $0.05 \%$ v/v (alkaline surfactant; Merz GmbH, Germany) in ultrapure water $(\mathrm{pH}=10.5)$

The $\mathrm{pH}$ of ultrapure water and $1 \mathrm{mM} \mathrm{NaCl}$ was adjusted with $1 \mathrm{M}$ sodium hydroxide $(\mathrm{NaOH}, 98.5 \%$; Acros Organics, Belgium). At the beginning of each experimental day, the system was rinsed with the respective carrier solution for at least $30 \mathrm{~min}$. The first run with an injected sample was performed to ensure a saturation of the membrane and the acquired fractogram was not used in subsequent analyses. At the end of every measurement day, the whole system was flushed with a mixture of ultrapure water and ethanol $(10 \%$ v/v EtOH; Merck, Germany) to avoid any crystallization in the tubing and separation channel. In order to remove any potential accumulations of AgNPs or silver chloride species inside the fluidic system and separation channel, the system 
was washed after ca. every 40-50 runs with an aqueous solution, which contained $0.5 \% \mathrm{v} / \mathrm{v}$ Mucasol and $1 \mathrm{mM}$ nitric acid (65\% p.a. $\mathrm{HNO}_{3}$; AppliCem, Germany).

For the characterization of the optical properties of the AgNPs independently from the AF4 system, a spectrophotometric system consisting of a DTMini-2-GS deuterium tungsten halogen light source (Ocean Optics, USA) and a USB4000 spectrophotometer (Ocean Optics, USA) was used. These devices were connected via optical fibers to the sample holder containing a $1 \times 1 \mathrm{~cm}$ quartz cuvette (Agilent Technologies). The USB4000 spectrophotometer was operated in a wavelength range of 200 to $850 \mathrm{~nm}$ with the Ocean View Spectroscopy Software Version 1.4.1. For the acquisition of UV/Vis spectra, the AgNP stock dispersions were diluted to a mass concentration of $5 \mathrm{mg} / \mathrm{L}$.

Size distributions as well as zeta-potentials of the AgNP batches were determined using the abovementioned ZetaSizer Nano-ZS equipment. The determination of the size distributions was performed with a mass concentration of $1 \mathrm{mg} / \mathrm{L}$ of the respective AgNPs in ultrapure water using disposable cuvettes (ZEN0040; Malver, UK). Zeta-potentials were determined with $2.5 \mathrm{mg} / \mathrm{L}$ AgNP dispersions in ultrapure water using folded capillary cells (DTS 1060; Malvern, UK). Electrophoretic mobility measurements were transformed to zeta-potentials using Henry's equation under the Smoluchowski's approximation using the software provided by the Malvern instrument [53, 54]. Aggregation experiments were conducted in a natural fjord water surface sample collected in Kiel Fjord $\left(54.368^{\circ} \mathrm{N}, 10.195^{\circ} \mathrm{E}\right.$; southwest Baltic Sea, north Germany). A total of $1.9 \mathrm{~mL}$ fjord water was spiked with $0.1 \mathrm{~mL}$ of $50 \mathrm{mg} / \mathrm{L}$ AgNP_LA dispersions. The fjord water sample was characterized, and the main parameters measured are presented elsewhere [55]. The determined $\mathrm{pH}$ (7.7), salinity (17.19), and total organic carbon $(277 \mu \mathrm{M})$ values are the expected for large estuarine-like systems, such as the Kiel Fjord.

In order to offer a complete approach for the analysis of AgNPs on the hyphenated AF4 system, we evaluated a large variety of settings: effect of carrier solution, effect of applied cross-flow, effect of focus time, recovery or quality of separation. The experiments were performed in single runs or duplicates. Table 1 summarizes all the experiments conducted with the hyphenated AF4 system.

\section{Results and discussion}

\section{Characterization of AgNP batches}

Prior to the conceptualization of any AF4 size separation experiment, the AgNPs coated with lipoic acid were carefully characterized in terms of size distribution, polydispersity, and zeta-potential (Table 2) as well as their optical properties (Fig. 1).

The measured $d_{H}$ for the three different AgNP batches were slightly higher than the diameters determined via transmission electron microscopy $\left(d_{T E M}\right)$ by the supplier. DLS measures hydrodynamic sizes, whereas TEM images are representative of hard-core sizes. The differences observed between the AgNP diameters measured using DLS and TEM are attributed

Table 1 Summary of the hyphenated AF4 experimental design. Experiments were conducted in single runs or duplicates

\begin{tabular}{|c|c|c|c|c|}
\hline \multirow[t]{2}{*}{ Test } & \multirow[t]{2}{*}{ Sample } & \multicolumn{3}{|l|}{ Elution conditions } \\
\hline & & Carrier solution & $\mathrm{V}_{\mathrm{x}}\left(\mathrm{mL} \min ^{-1}\right)$ & Focus time (min) \\
\hline $\begin{array}{l}\text { Effect of carrier solution } \\
\text { and applied cross-flow }\end{array}$ & $\begin{array}{l}\text { Individual AgNP_LA fractions } \\
\quad(20 \mathrm{~nm}, 50 \mathrm{~nm} \text {, and } 80 \mathrm{~nm})\end{array}$ & $\begin{array}{l}\text { Water } \mathrm{pH} 8 \\
0.05 \% \mathrm{v} / \mathrm{v} \text { Mucasol } \\
1 \mathrm{mM} \mathrm{NaCl}\end{array}$ & $\begin{array}{l}0.0 \\
0.2 \\
0.5 \\
1\end{array}$ & 10 \\
\hline Effect of focus time & $50 \mathrm{~nm}$ AgNP_LA & Water $\mathrm{pH} 8$ & 0.5 & $\begin{array}{l}2 \\
5 \\
10\end{array}$ \\
\hline Recovery & $20 \mathrm{~nm}$ AgNP_LA & $\begin{array}{l}\text { Water } \mathrm{pH} 8 \\
0.05 \% \mathrm{v} / \mathrm{v} \text { Mucasol } \\
1 \mathrm{mM} \mathrm{NaCl}\end{array}$ & $\begin{array}{l}0.0 \\
0.2 \\
0.5 \\
0.7 \\
1\end{array}$ & 10 \\
\hline Quality of separation & $\begin{array}{l}\text { Mixture 1:120 nm and } 50 \mathrm{~nm} \text { AgNP_LA } \\
\text { Mixture 1:120 nm and } 80 \mathrm{~nm} \text { AgNP_LA }\end{array}$ & $\begin{array}{l}\text { Water } \mathrm{pH} 8 \\
\text { Water } \mathrm{pH} 8 \\
0.05 \% \mathrm{v} / \mathrm{v} \mathrm{Mucasol} \\
1 \mathrm{mM} \mathrm{NaCl}\end{array}$ & $\begin{array}{l}0.5 \\
1 \\
0.3 \\
0.5 \\
0.7\end{array}$ & 10 \\
\hline $\begin{array}{l}\text { Separation of AgNPs } \\
\text { in marine coastal waters }\end{array}$ & $\begin{array}{l}\text { Mixture 1:120 nm and } 80 \mathrm{~nm} \text { AgNP_LA } \\
\text { spiked into fjord water }\end{array}$ & $0.05 \% \mathrm{v} / \mathrm{v}$ Mucasol & 0.5 & 10 \\
\hline
\end{tabular}


Table 2 Size characterization of AgNP_LA in batch and in AF4-UV/ Vis-DLS system. Results obtained with the ZetaSizer Nano-ZS for the hydrodynamic diameter $d_{H}$, polydispersity index $P d I$, and zeta-potential $\zeta$. Parenthesized values were determined ca. 4 months after purchasing the AgNPs; all other values were determined directly after delivery. AF4 experiments were conducted within 2 months after AgNP delivery. Values shown in the table for 1:1 AgNP LA mixtures were acquired with the best experimental conditions

\begin{tabular}{|c|c|c|c|c|c|c|c|c|c|}
\hline \multirow[t]{2}{*}{ Sample } & \multicolumn{5}{|c|}{ Batch characterization } & \multicolumn{4}{|c|}{ AF4-UV/Vis-DLS system } \\
\hline & 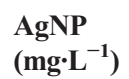 & $d_{H}(\mathrm{~nm})$ & $\begin{array}{l}d_{T E M} \\
(\mathrm{~nm})^{\mathrm{a}}\end{array}$ & $P d I$ & $\zeta(\mathrm{mV})$ & Sample & $\begin{array}{l}\operatorname{AgNP} \\
\left(\mathbf{m g} \cdot \mathbf{L}^{-1}\right)\end{array}$ & Carrier solution & $d_{H}(\mathrm{~nm})$ \\
\hline 20 nm AgNP_LA & 2.5 & $\begin{array}{l}28.5 \pm 1.0 \\
(39.3 \pm 1.7)\end{array}$ & $20.4 \pm 3.0$ & $\begin{array}{l}0.24 \pm 0.03 \\
(0.32 \pm 0.01)\end{array}$ & $-26.7 \pm 4.4$ & $20 \mathrm{~nm}$ AgNP_LA ${ }^{\mathrm{b}}$ & 50 & $\begin{array}{l}\text { Water } \mathrm{pH} 8 \\
0.05 \% \mathrm{v} / \mathrm{v} \text { Mucasol } \\
1 \mathrm{mM} \mathrm{NaCl}\end{array}$ & $\begin{array}{l}35 \\
42 \\
50\end{array}$ \\
\hline $50 \mathrm{~nm}$ AgNP_LA & 2.5 & $\begin{array}{l}52.2 \pm 0.6 \\
(64.3 \pm 2.3)\end{array}$ & $48.6 \pm 4.5$ & $\begin{array}{l}0.12 \pm 0.02 \\
(0.20 \pm 0.01)\end{array}$ & $-20.1 \pm 2.5$ & $\begin{array}{l}20 \mathrm{~nm} \text { AgNP_LA } \\
\quad \text { in mixture } 1: 1^{\mathrm{c}}\end{array}$ & 50 & $\begin{array}{l}\text { Water } \mathrm{pH} 8 \\
0.05 \% \mathrm{v} / \mathrm{v} \text { Mucasol } \\
1 \mathrm{mM} \mathrm{NaCl}\end{array}$ & $\begin{array}{l}55 \\
55 \\
55\end{array}$ \\
\hline 80 nm AgNP_LA & 2.5 & $\begin{array}{l}97.3 \pm 0.8 \\
(101.6 \pm 1.1)\end{array}$ & $83.2 \pm 10.4$ & $\begin{array}{l}0.07 \pm 0.01 \\
(0.09 \pm 0.02)\end{array}$ & $-32.0 \pm 2.0$ & $\begin{array}{l}80 \mathrm{~nm} \text { AgNP_LA } \\
\quad \text { in mixture } 1: 1^{\mathrm{c}}\end{array}$ & 50 & $\begin{array}{l}\text { Water } \mathrm{pH} 8 \\
0.05 \% \mathrm{v} / \mathrm{v} \text { Mucasol } \\
1 \mathrm{mM} \mathrm{NaCl}\end{array}$ & $\begin{array}{l}105 \\
120 \\
125\end{array}$ \\
\hline
\end{tabular}

${ }^{\text {a }}$ Particle diameters $\left(d_{T E M}\right)$ determined with transmission electron microscopy were taken from the supplier's specification sheet for the individual AgNP batches

${ }^{\mathrm{b}} 20 \mathrm{~nm}$ AgNP_LA $d_{H}$ values for different carrier solutions (Fig. 3c)

${ }^{\mathrm{c}}$ Different size fractions in 1:1 mixture of 20- and 80-nm AgNP_LA (Fig. 7)

to the LA coating thickness and polydispersity of the AgNP samples. The 80-nm AgNP_LA batch showed the narrowest and the 20-nm particles the widest distribution, with polydispersity indices $(P d I)$ of $0.07 \pm 0.01$ and $0.24 \pm 0.03$, respectively. The determined negative zeta-potentials $(\zeta$ ) (a measure for the formation of an electrochemical double layer and its strength) indicate that the coating with lipoic acid produced a negative surface charge by deprotonation of the carboxyl group. According to the DLVO theory [56, 57], this leads to an electrostatic stabilization of the particles. The long-term stability of the lipoic acid-coated AgNPs was investigated in terms of $d_{H}$ and $P d I$ after ca. 4 months of storage at $5{ }^{\circ} \mathrm{C}$ (parenthesized values in Table 2). For all three batches, $d_{H}$ and $P d I$ increased, especially for the 20 - and $50-\mathrm{nm}$ particles with a less negative zeta-potential and therefore weaker repulsion forces compared to the $80-\mathrm{nm}$ particles. This observed increase in size and polydispersity of the AgNPs may be due to the highly concentrated stock dispersion $(1 \mathrm{~g} / \mathrm{L})$, where the probability for a diffusion-controlled approach of the nanoparticles is much higher than that in dilute dispersions.

The different AgNP_LA batches featured absorbance spectra with absorbance maxima of $\lambda_{\max }(d=20 \mathrm{~nm})=399 \mathrm{~nm}$, $\lambda_{\max }(d=50 \mathrm{~nm})=422 \mathrm{~nm}$, and $\lambda_{\max }(\mathrm{d}=80 \mathrm{~nm})=469 \mathrm{~nm}$ generated by surface plasmon resonance. The spectral
Fig. $1 \mathrm{UV} / \mathrm{V}$ is spectra of the individual AgNP_LA batches and of a 1:1 mixture of 20-nm and 80$\mathrm{nm}$ particles. All spectra were acquired in ultrapure water

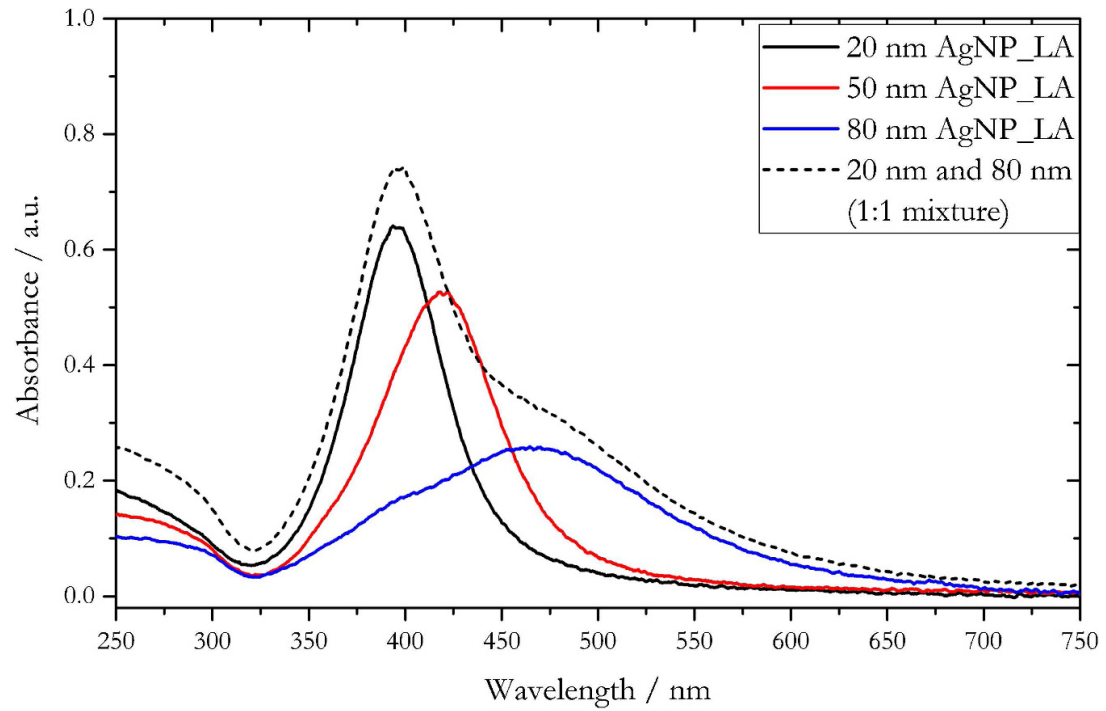


position, peak height, and bandwidth of those characteristic absorption bands are determined by the particle composition, shape, and size as well as the dielectric characteristics of the surrounding environment [58]. The observable red shift of the absorption band with increasing particle diameter can be ascribed to surface plasmon resonances. Multipole resonances can be excited for particles with elevated diameters which leads to a reduction of the depolarization field, where electrons do not move in phase. This retardation effect results in a red shift of the absorption band [58]. The observable peak broadening and decrease of intensity with increased diameter can be ascribed to radiative losses, which contributes to the plasmon damping [58]. The recorded spectrum of a 1:1 mixture of 20and 80-nm AgNPs (dashed line in Fig. 1) can be regarded as superposition of the two individual spectra. No shift of the peak position and bandwidth was observed when using different liquid media (ultrapure water, $0.05 \% \mathrm{v} / \mathrm{v}$ Mucasol and $1 \mathrm{mM} \mathrm{NaCl}$; please be referred to Fig. S1). Thus, we did not find significant oxidation and/or aggregation of AgNP_LA in the studied media. Based on a previous study [55], we hypothesized that oxidation, in case it occurred, would take place after the aggregation and later sedimentation of the AgNPs.

The characteristic optical property of AgNPs of different sizes enables the determination of different AgNP size fractions using UV/Vis spectroscopy and is therefore a powerful detection tool for AF4 size separation approaches.

\section{AF4 experiments with individual AgNP batches}

\section{Quantity of injected particles}

In order to avoid a sample overload of the AF4 channel, it is recommended to inject $10^{7}$ to $10^{10}$ particles per run [59]. Higher particle numbers may result in a depression of retention time $\left(t_{R}\right)$ and an asymmetric shape (fronting or tailing) of the recorded peak [60-62]. With very low injected particle numbers, their detection can be negatively affected in terms of limit of detection and signal to noise ratio of the respective detection system. Fractograms for the injection of 10 and $50 \mathrm{mg} / \mathrm{L}$ dispersions of $20-\mathrm{nm}$ AgNP_LA using the $20-\mu \mathrm{L}$ injection loop, which is equivalent to the injection of $4.4 \cdot 10^{9}$ and $2.2 \cdot 10^{10}$ AgNPs, respectively, are shown in Fig. 2.

For both fractograms, a symmetric peak was obtained with a $t_{R}$ of $12.1 \mathrm{~min}$. The fractogram of the $10 \mathrm{mg} / \mathrm{L}$ dispersion showed a low signal to noise ratio compared to $50 \mathrm{mg} / \mathrm{L}$, with five times lower peak intensity and area. Furthermore, the particle fraction could not be analyzed in terms of $d_{H}$ via DLS as one can assume that the concentration was below the limit of detection, whereas DLS reading was obtained for the $50 \mathrm{mg} / \mathrm{L}$ dispersion. However, the recorded hydrodynamic diameter (with $d_{H}=60 \mathrm{~nm}$ at the minimum) is higher than the diameter determined in the batch experiments for the 20-nm AgNP_LA fraction (Table 2). This observation can be metrologically explained by a perturbation of the diffusioncontrolled movement due to the applied flow in the online coupled DLS measurement cell [63]. Physico-chemical explanations for the observation of this bias will be given throughout the discussion below. Throughout our study, we observed a U-shaped distribution of the DLS data as a function of the elution time. This was also observed in a variety of other studies but the understanding of its appearance remains unclear. It can be hypothesized that the U-shaped distribution is related to low particle concentrations at the beginning and end of the elution peak, to the presence of larger aggregates in solutions or to a change of the shape of the particles during the separation and elution process [34]. In addition to the main AgNP peak, the AF4 fractograms feature void peaks (at $t_{R}=$
Fig. 2 Fractograms of 20-nm AgNP_LA for $10 \mathrm{mg} / \mathrm{L}$ and $50 \mathrm{mg} / \mathrm{L}$ dispersions using a 20 $\mu \mathrm{L}$ injection loop, $1 \mathrm{mM} \mathrm{NaCl}$ as carrier solution, PES membrane, and a constant cross-flow of $V_{x}=$ $0.5 \mathrm{~mL} / \mathrm{min}$. Dotted data points indicate hydrodynamic diameter (right y-axis)

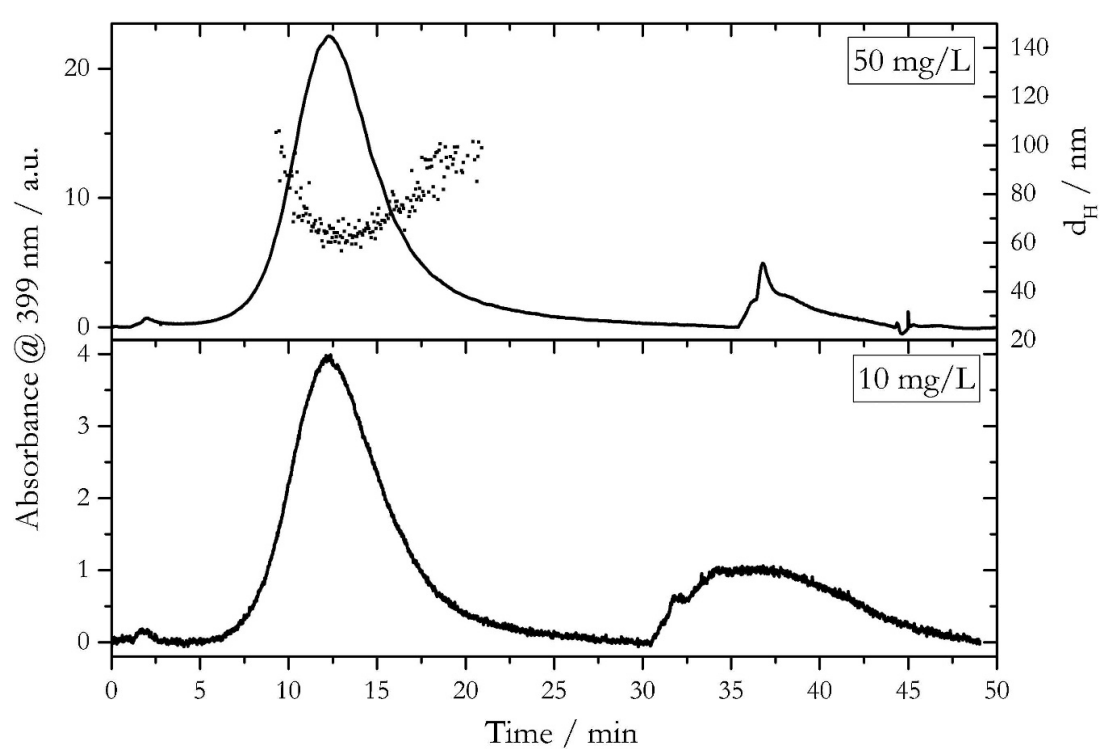


2 min in Fig. 2) due to unfocussed AgNPs, and release peaks (at $t_{R}=30 \mathrm{~min}$ for $10 \mathrm{mg} / \mathrm{L}$ and at $t_{R}=35 \mathrm{~min}$ for $50 \mathrm{mg} / \mathrm{L}$ dispersions in Fig. 2) due to retained AgNPs. The time shift of the release peak was caused by a 5 min earlier start of the flushing step for the $10 \mathrm{mg} / \mathrm{L}$ dispersion. The appearance and nature of the void and release peaks are further discussed throughout the following sections.

Based on the results shown in Fig. 2, we applied injections of $50 \mathrm{mg} / \mathrm{L}$ dispersions using a $20-\mu \mathrm{L}$ loop, and of $10 \mathrm{mg} / \mathrm{L}$ dispersions using a $100-\mu \mathrm{L}$ loop throughout the study presented herein. This was equivalent to a quantity of $2.2 \cdot 10^{10}$ particles for $20-\mathrm{nm}$ AgNP_LA, $1.7 \cdot 10^{9}$ particles for $50-\mathrm{nm}$ AgNP_LA, and $3.4 \cdot 10^{8}$ particles for $80-n m$ AgNP_LA per injection.

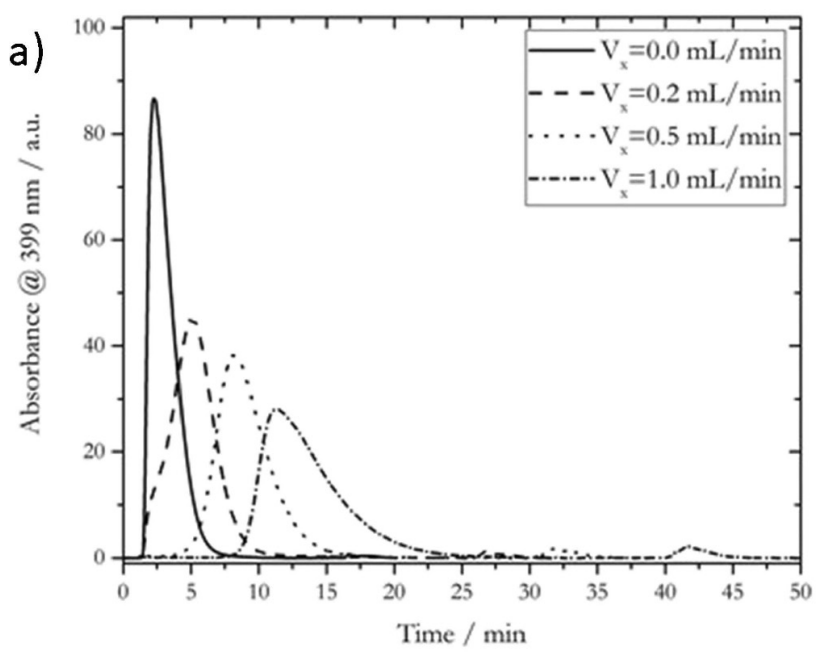

\section{Effect of carrier solution and applied cross-flow}

The most characteristic feature of AF4 is the applied crossflow $\left(\mathrm{V}_{\mathrm{x}}\right)$ : a field directed perpendicular to the parabolic velocity channel flow profile which determines the nature and appearance of the peaks in AF4 fractograms. The effect of different cross-flows on the fractograms and $t_{R}$ of the 20-nm AgNP LA batch is shown in Fig. 3a and b. Fractograms for 20 -nm AgNP_LA for $0.05 \% \mathrm{v} / \mathrm{v}$ Mucasol and $1 \mathrm{mM} \mathrm{NaCl}$ as carrier solution as well as data for 50- and 80-nm AgNP_LA batches are presented in Fig. S2 to Fig. S4.

A shift of the $t_{R}$ as well as a broadening of the elution peaks was observed when increasing the applied cross-flow. The cross-flow affects the diffusion-driven transport of the injected

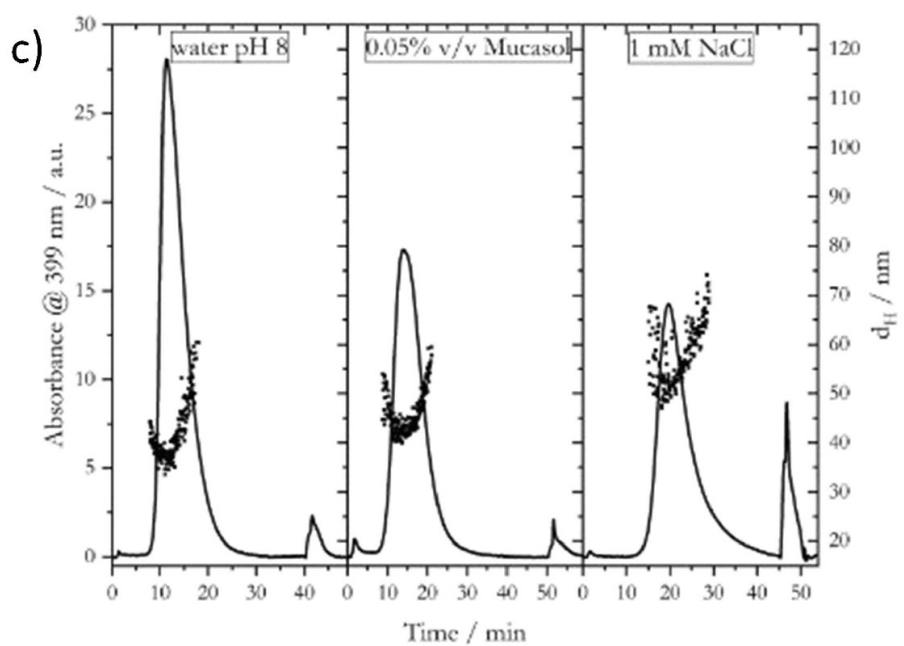

Fig. 3 Effect of applied cross-flow and carrier solution on 20-nm AgNP LA fractograms, retention time, and hydrodynamic diameter. $\bar{a}$ Fractograms obtained for different cross-flows and water $\mathrm{pH} 8$ as carrier

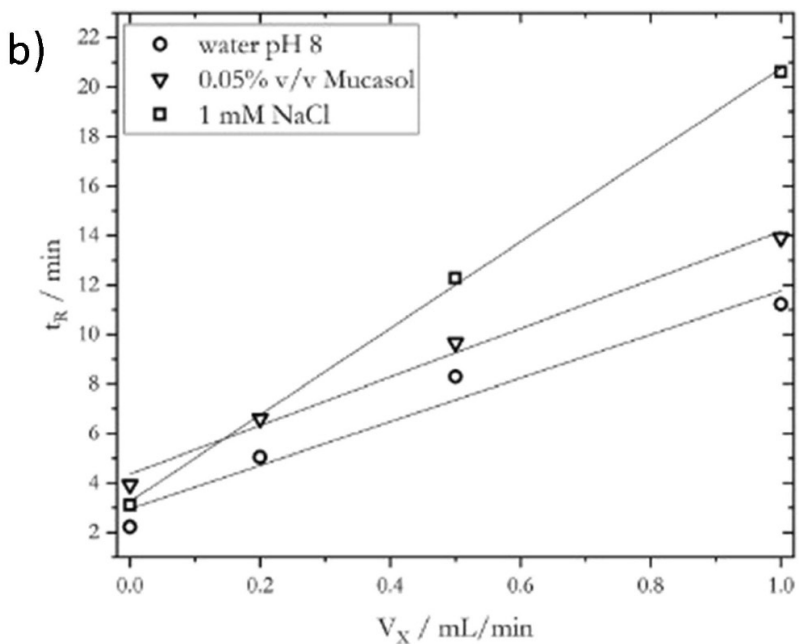

Time / $\min$

solution. b Retention time $\left(t_{R}\right)$ at different cross-flows and carrier solutions. $\mathbf{c}$ Fractograms and hydrodynamic diameter for different carrier solutions, $V_{x}=1.0 \mathrm{~mL} / \mathrm{min}$ 
particles perpendicular to parabolic velocity profile of the channel flow, and thus the vertical distance of the particles to the separation membrane. Particles of the same diameter are located closer to the separation membrane with increasing cross-flow, which means that they are affected by lower channel flow rate and broader velocity distribution, resulting in slower elution (longer $t_{R}$ ) and broadening of the elution peak. The relationship between $t_{R}$ and applied cross-flow as a function of particle diameter can be assumed to be linear (Fig. 3b) according to the following first-order approximation [60]:

$t_{R}=\frac{\pi \eta w^{2} t^{0} d_{H}}{2 k_{B} T V^{0}} \cdot V_{x}$,

with the solvent viscosity $\eta$, the channel height $\omega$, the time required for the carrier solution to pass through the channel (void time) $t^{0}$, the Boltzmann constant $k_{B}$, the temperature $T$, and the geometric volume of the channel $V^{0}$. Based on this equation, particles of different diameter feature a characteristic $t_{R}$, which enables a size separation via AF4 (see section "AF4 experiments with AgNP mixtures").

Another important parameter, which affects the performance of AF4 systems, is the selected carrier solution. It can be easily modified in terms of composition, ionic strength, and $\mathrm{pH}$ value in order to ensure good quality of acquired fractograms and size separation of polydisperse nanoparticle samples. For AF4 experiments, it is recommended to use carrier solutions in a near-neutral $\mathrm{pH}$ range to ensure safe system operating conditions [59]. Moreover, the physico-chemical properties of the carrier solution should nearly mimic the properties of the injected nanoparticle sample in order to avoid perturbations such as aggregation, changes in particle and membrane charge or double-layer thickness and particlemembrane interactions [26]. Because of our future goal to characterize seawater samples, a $\mathrm{pH}$ of $\sim 8$ was chosen for ultrapure water and $1 \mathrm{mM} \mathrm{NaCl}$ as carrier solutions. Additionally, a carrier solution containing $0.05 \% \mathrm{v} / \mathrm{v}$ of the alkaline surfactant Mucasol was tested. Surfactants were applied in several studies in order to control the interactions between particles and membrane [26, 59]. In general, the less the interactions particle-membrane and particle-particle, the shorter $t_{R}$ [64-66].

The 20-nm AgNP_LA batch showed the highest $t_{R}$ with $1 \mathrm{mM} \mathrm{NaCl}$ as carrier solution, and the lowest with water pH 8 (Fig. 3b and c). This observation was consistent throughout the different AgNP_LA batches (see Fig. S5). As the ionic strength is increased, the electrochemical double layer is more compressed of both the negatively charged PES membrane $(\zeta \sim-10 \mathrm{mV}$ was assumed for the PES membrane at $\mathrm{pH} \sim 8$ [67]) and the negatively charged AgNP_LA batches. This compression resulted in a shorter Debye length and therefore a shorter vertical distance between particles and membrane [59]. As the particles approached closer to the membrane surface due to less repulsive forces, they were affected by a slower channel flow rate and broader velocity distribution, which caused longer $t_{R}$ and peak broadening. When using $0.05 \% \mathrm{v} / \mathrm{v}$ Mucasol as carrier solution, slightly longer $t_{R}$ compared to water $\mathrm{pH} 8$ but noticeable shorter times compared to $1 \mathrm{mM} \mathrm{NaCl}$ were observed (Fig. $3 \mathrm{~b}$ and c). Any statement about the ionic strength of the Mucasol-containing carrier solution is difficult due to the unknown concentrations of the containing ionic species in solution. However, the $\mathrm{pH}$ of the $0.05 \% \mathrm{v} / \mathrm{v}$ Mucasol solution $(\mathrm{pH}=10.5)$ is $2.5 \mathrm{pH}$ units higher than the values for the other used carrier solutions. This $\mathrm{pH}$ increase could have caused a shift in the zeta-potential of the PES membrane of around 5 to $10 \mathrm{mV}$ to more negative values, compared to using solutions at $\mathrm{pH} \sim 8$ [67]. The same effect on the zetapotential was observed for negatively charged AgNPs when increasing the $\mathrm{pH}$ value of the surrounding solution [68]. This higher charge of both the PES membrane and the AgNPs when using $0.05 \% \mathrm{v} / \mathrm{v}$ Mucasol at $\mathrm{pH}=10.5$ led to stronger repulsive forces and therefore shorter $t_{R}$ compared to $1 \mathrm{mM} \mathrm{NaCl}$. Besides the shift in $t_{R}$ due to the compression of the electrochemical double layer, the $d_{H}$ of the particles was also increased when using carrier solutions with a higher ionic strength than water $\mathrm{pH} 8$, as shown in Fig. 3c. Increases of about $7 \mathrm{~nm}$ and $15 \mathrm{~nm}$ of $d_{H}$ were observed for $0.05 \% \mathrm{v} / \mathrm{v}$ Mucasol and $1 \mathrm{mM} \mathrm{NaCl}$, respectively. According to the DLVO theory, increased ionic strength destabilizes electrostatically stabilized systems, thus favoring the particle aggregation and causing an increase of $d_{H}$ and $t_{R}$. The more negative charge of the particles when using $0.05 \% \mathrm{v} / \mathrm{v}$ Mucasol compared to $1 \mathrm{mM} \mathrm{NaCl}$, due to the different $\mathrm{pH}$ values of the solutions, caused stronger repulsive forces between the AgNPs and thus an attenuation of the aggregation process.

\section{Effect of focus time}

The focusing step in AF4 experiments (Table S1, step 4) ensures that injected particles will be focused sufficiently in a horizontal zone which is as small as possible [69]. Furthermore, and most important, a vertical relaxation of the injected particles takes place as a function of their individual diffusion coefficients and applied cross-flow [70]. Thus, the duration of the focusing step and the applied cross-flow affects the nature and quality of the obtained fractogram [71] as shown in Fig. 4.

The signal of the void peak decreased with longer focus times (inset of Fig. 4a). For example, the signal of the void peak for a focus time of 5 min was only half the intensity of the peak acquired with a focus time of 2 min in step 4, while the appearance of a void peak was almost negligible for 10 min of focusing time. This observation can be ascribed to an insufficient focus step for shorter focus times, leading to the pre-elution of unfocused nanoparticles. Additionally, a 


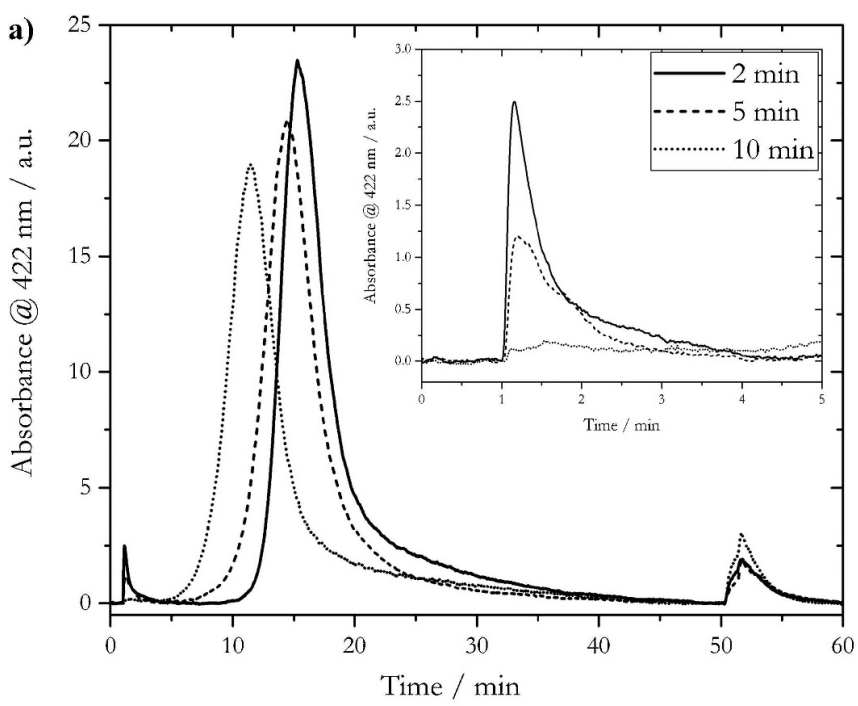

Fig. 4 Effect of different focus times on the fractograms and $d_{H}$ of 50-nm AgNP LA with water $\mathrm{pH} 8$ as carrier solution. a Fractograms acquired with $\bar{V}_{x}=0.5 \mathrm{~mL} / \mathrm{min}$; inset shows the void peak. b Hydrodynamic

delayed elution of the 50-nm AgNP_LA batch with shorter focus times was observed, e.g., the elution peak for 10-min focus time had its maximum at $11.5 \mathrm{~min}$, whereas the maximum for 2-min focus time was at $15.3 \mathrm{~min}$. During injection, particles are accumulated near the membrane on the bottom of the channel. Once the injection flow is switched off, relaxation processes affect the particles producing a diffusion-controlled transport of the particles towards the center of the channel in accordance with their respective diffusion coefficients. If this time for relaxation (focus time) is chosen too short, insufficient relaxed particles are affected by slower speed of the carrier solution during the elution step, compared to wellrelaxed particle spots. This occurs due to a closer distance of the particles to the membrane, and the parabolic velocity profile. The focus time not only affects the position of the elution peak, but also its signal intensity. It is assumed that particles are more favorable for the attachment on the membrane in the focusing zone as a consequence of longer applied high field strengths [60]. This is in accordance with a more intense release peak for a focus time of 10 min compared to smaller release peaks when shorter focus times were applied (at $t_{R}>$ $50 \mathrm{~min}$ in Fig. 4a). Release peaks are generated due to reversibly attached particles to the membrane, which are eluted in the flushing step when no cross-flow is applied.

The duration of the focus time also affected the $d_{H}$ of the detected fractions, as shown in Fig. 4b. When there was no cross-flow and a 5-min focus step was applied, particles with $d_{H}=59 \mathrm{~nm}$ were detected via online DLS. In contrast, a 10min focusing step led to the detection of a AgNP size fraction with $d_{H}=70 \mathrm{~nm}$. This observed increase of $d_{H}$ was caused by a higher probability of particle aggregation due to high focus field strengths, coming along with higher particle concentration in a very small zone and therefore closer particle-particle

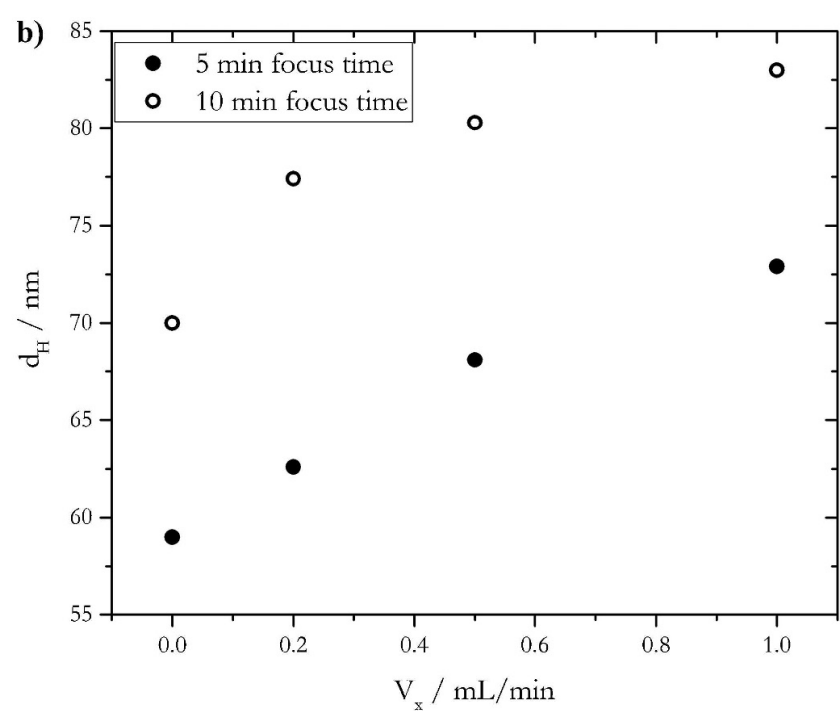

diameters determined with online coupled DLS at $t_{R}$ of absorbance maximum for different applied cross-flows and focus times

distance [60]. The same effect was observed as a consequence of an increased applied cross-flow (Fig. 4b). The $d_{H}$ was ca. $15 \mathrm{~nm}$ higher with $V_{x}=1.0 \mathrm{~mL} / \mathrm{min}$, compared to no applied cross-flow for both 5-min and 10-min focus times.

\section{Recovery}

The recovery of the sample is a suitable parameter for the evaluation of the loss of particles as a consequence of their accumulation on the separation membrane due to applied cross-flows in AF4 experiments. Figure 5 shows the recovery for 20-nm AgNP_LA with different carrier solutions as a function of the applied cross-flow. Here, the recovery is expressed as a normalized peak area, with a normalized peak area of 1.0 being equivalent to a $100 \%$ recovery. Normalized peak areas were obtained from the respective fractograms by dividing the area of the elution peak (Fig. 5a) or the sum of the areas of elution and release peak (Fig. 5b) by the area obtained for $V_{x}=0.0 \mathrm{~mL} / \mathrm{min}$. Thus, it was assumed that $100 \%$ recovery was achieved when no cross-flow was applied.

Increased cross-flows affected the recovery of the 20-nm AgNP_LA sample negatively: ca. $10 \%$ decrease in recovery for cross-flows of 0.5 and $1.0 \mathrm{~mL} / \mathrm{min}$, when water $\mathrm{pH} 8$ and $0.05 \% \mathrm{v} / \mathrm{v}$ Mucasol were used as carrier solutions. Previous studies demonstrated the effect of high cross-flows on the increment of the membrane fouling, and therefore the decrease of the sample recovery [72]. This can be explained due to more favorable inter-particle associations, and both reversible and irreversible particle adhesion to the membrane because of high field strengths [73, 74]. This effect was even more predominant when using $1 \mathrm{mM} \mathrm{NaCl}$ as carrier solution with recoveries of $80 \%$ and $73 \%$ for $V_{x}=$ 0.5 and $1.0 \mathrm{~mL} / \mathrm{min}$ (Fig. 5a), respectively, as a 

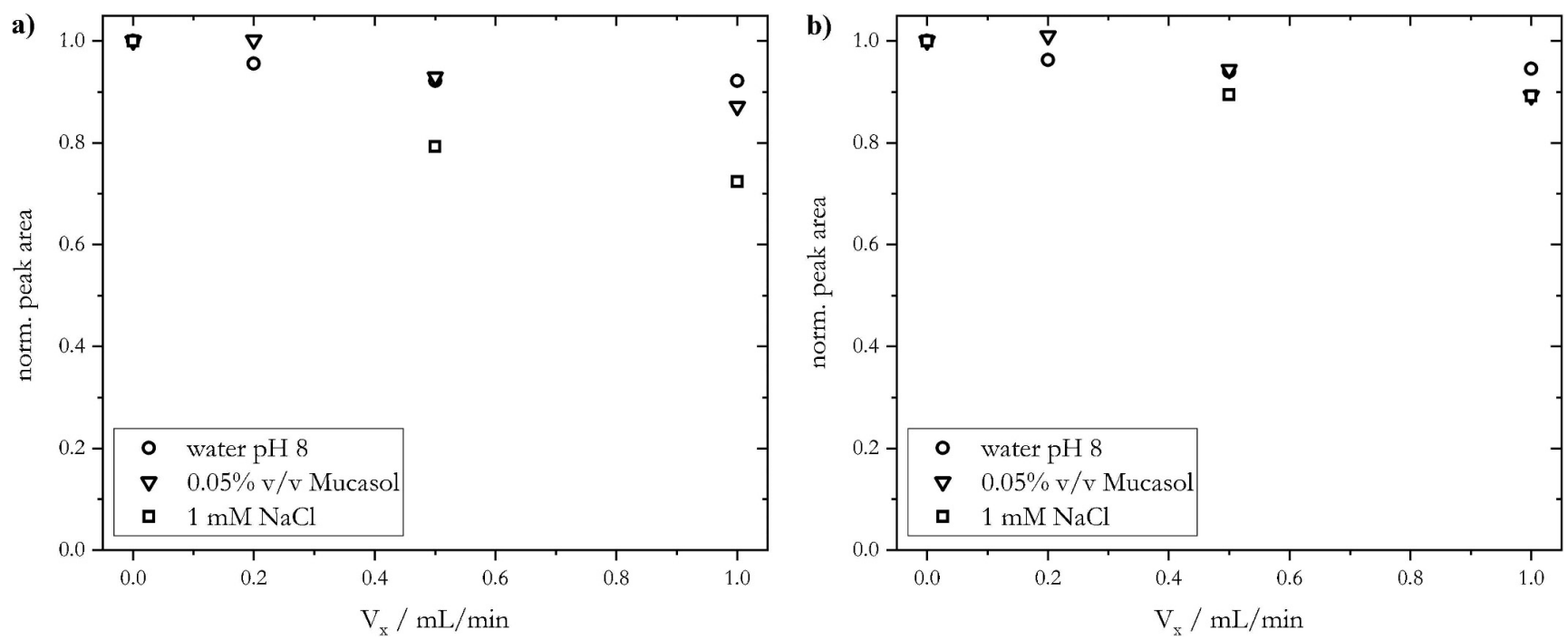

Fig. 5 Recovery, expressed as normalized peak area, of 20-nm AgNP LA for different carrier solutions: ultrapure water at $\mathrm{pH} 8$ (circles), $0.05 \%$ Mucasol (triangles), and $1 \mathrm{mM} \mathrm{NaCl}$ (squares) as a function of the applied cross-flow

consequence of an elevated ionic strength affecting particle-particle and particle-membrane interactions. Yet a considerable AgNP fraction was reversibly attached to the membrane, resulting in the presence of a dominant release peak, and thus a shift of recovery to values up to $90 \%$ when taking into account the sum of the area of the elution and release peaks (Fig. 5b). The reversibly attached particles on the membrane, either in the focusing zone or in the separation zone, were released when turning off the cross-flow in the flushing step (step 6, Table S1). This reentrainment produced a release peak in the respective fractograms (Fig. 3a and Fig. S2). The area of this peak increased with increasing cross-flows. It was further observed that the sum of both areas cannot be correlated to a recovery of $100 \%$ with applied cross-flow for all carrier solutions (Fig. 5b). Thus, the presence of irreversibly attached particles or aggregation processes can be assumed, most prominently in the focusing zone, where high field strengths were applied [60]. In this zone, a change of color of the membrane was observed after several runs by a visual inspection, supporting the argument of irreversible accumulation of AgNPs.

\section{AF4 experiments with AgNP mixtures}

\section{Quality of separation}

Based on Eq. (1) and the results presented in section 3.2, fractograms of a mixture of particles of two different sizes should feature two distinct, and most preferable baseline separated elution peaks, each referring to one particle size fraction. Figure 6 shows fractograms for a 1:1 mixture of 20 - and 50-nm AgNP_LA particles at two different cross-flows.
Although two maxima were obtained for each fractogram, corresponding to 20 - and 50-nm particles, the two elution peaks overlapped, which indicates an insufficient separation of the size fractions, for both $V_{x}=0.5 \mathrm{~mL} / \mathrm{min}$ and $V_{x}=$ $1.0 \mathrm{~mL} / \mathrm{min}$. The height of the absorption signals decreased by ca. 6 units for a cross-flow of $1.0 \mathrm{~mL} / \mathrm{min}$ compared to $0.5 \mathrm{~mL} / \mathrm{min}$. This was in accordance with previous observations that a higher cross-flow generates a higher loss of AgNPs due to the attachment on the membrane and more favorable particle-particle interactions. The existence of aggregated species was also indicated by the obtained DLS signal. The $d_{H}$ of the mixture of particles increased by $12 \mathrm{~nm}$ at the minimum, showing a broader distribution for $V_{x}=$ $1.0 \mathrm{~mL} / \mathrm{min}$, when compared to $V_{x}=0.5 \mathrm{~mL} / \mathrm{min}$. Considering $d_{H}$, no distinct separate signals for the 20- and the 50-nm AgNP LA size fraction were obtained. Thus, it can be assumed that the $d_{H} \mathrm{~s}$ as well as the individual diffusion coefficients were too similar, which precluded an efficient separation. Presumably, higher applied cross-flows would have led to a better separation, but at the expense of much longer elution times and much greater particle losses due to aggregation and membrane attachment.

A better size separation of AgNPs was achieved when using a 1:1 mixture of 20- and 80-nm AgNP_LA (Fig. 7).

The maxima of the elution peaks for the individually applied cross-flows and carrier solutions were in good agreement with the $t_{R}$ obtained for the single AgNP_LA batch experiments (e.g., Fig. S5). Longest $t_{R}$ was determined with $1 \mathrm{mM} \mathrm{NaCl}$ and earliest elution was observed with water $\mathrm{pH} 8$ as carrier solution due to the different ionic strengths of the solutions, affecting particle-particle and particle-membrane interactions. Best separation of 20-nm and 80-nm AgNP_LA was achieved with the carrier solutions $0.05 \% \mathrm{v} / \mathrm{v}$ Mucasol and $1 \mathrm{mM} \mathrm{NaCl}$ and applied cross-flows of $\geq 0.5 \mathrm{~mL} / \mathrm{min}$. 
Fig. 6 Fractograms and online determined hydrodynamic diameter of a 1:1 mixture of 20and 50-nm AgNP_LA for different cross-flows and water $\mathrm{pH} 8$ as carrier solution

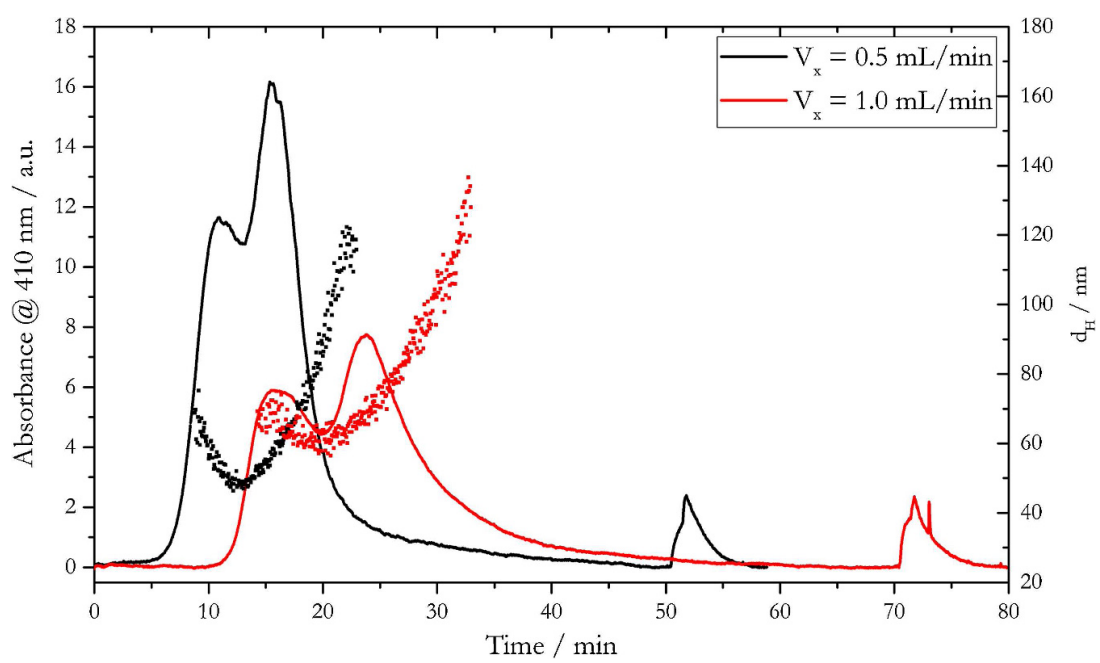

Under those conditions, the two peaks were separated considerably closer to the baseline than for $V_{x}=0.3 \mathrm{~mL} / \mathrm{min}$ and water $\mathrm{pH} 8$ as carrier solution. The absorbance values at the minimum between the two separated elution peaks were 0.6 and 0.4 a.u. for the applied cross-flows of $0.5 \mathrm{~mL} / \mathrm{min}$ and $0.7 \mathrm{~mL} / \mathrm{min}$, respectively, for both $0.05 \% \mathrm{v} / \mathrm{v}$ Mucasol and $1 \mathrm{mM} \mathrm{NaCl}$. However, the slightly better separation for $V_{x}$ $=0.7 \mathrm{~mL} / \mathrm{min}$ compared to $0.5 \mathrm{~mL} / \mathrm{min}$ came with much longer durations (10 to $15 \mathrm{~min}$ ) of the separation experiments. The fractograms obtained with $0.05 \% \mathrm{v} / \mathrm{v}$ Mucasol as carrier solution feature a much more intense void peak (at $t_{R}=2 \mathrm{~min}$ ) than fractograms for water $\mathrm{pH} 8$ and $1 \mathrm{mM}$ $\mathrm{NaCl}$, as also observed in the single batch experiments (e.g., Fig. 3c and Fig. S2 to S4). This feature may be explained by the formation of micelles. The applied high field strengths during the focusing step could have induced a preconcentration of the surfactant molecules, which exceeded the critical micelle formation concentration. It was found in earlier studies that the formation of micelles can generate an undesired elution, which interfere with the detection of nanoparticles [59].
Higher tendency for particle aggregation can be assumed for $0.05 \% \mathrm{v} / \mathrm{v}$ Mucasol and $1 \mathrm{mM} \mathrm{NaCl}$ compared to water $\mathrm{pH} 8$, which agrees with the lower detected intensity of the peaks for these carrier solutions and shift to longer elution times (Fig. 7). Those aggregates were also detectable with the hyphenated DLS detector $\left(d_{H}\right.$ in Fig. 7). For all carrier solutions, two distinct signals were obtained for $d_{H}$, correlating to the separated 20-nm and 80-nm AgNP LA fractions. However, compared to water $\mathrm{pH} 8, d_{H}$ of the 80 -nm fraction was increased by ca. $15 \mathrm{~nm}$ and $20 \mathrm{~nm}$ when using $0.05 \% \mathrm{v} / \mathrm{v}$ Mucasol and $1 \mathrm{mM} \mathrm{NaCl}$, respectively, due to favorable aggregation processes as a consequence of the increased ionic strengths of the carrier solutions. The aggregation was also linked to the detection of a broader size distribution for both 20-nm and 80-nm AgNP_LA fractions when using 0.05\% v/v Mucasol and $1 \mathrm{mM} \mathrm{NaCl}$ as carrier solutions.

\section{Separation of AgNPs in marine coastal waters as a case study}

As AF4 is a sensitive technique to determine distinct signals for different nanoparticle size fractions, we assumed that this

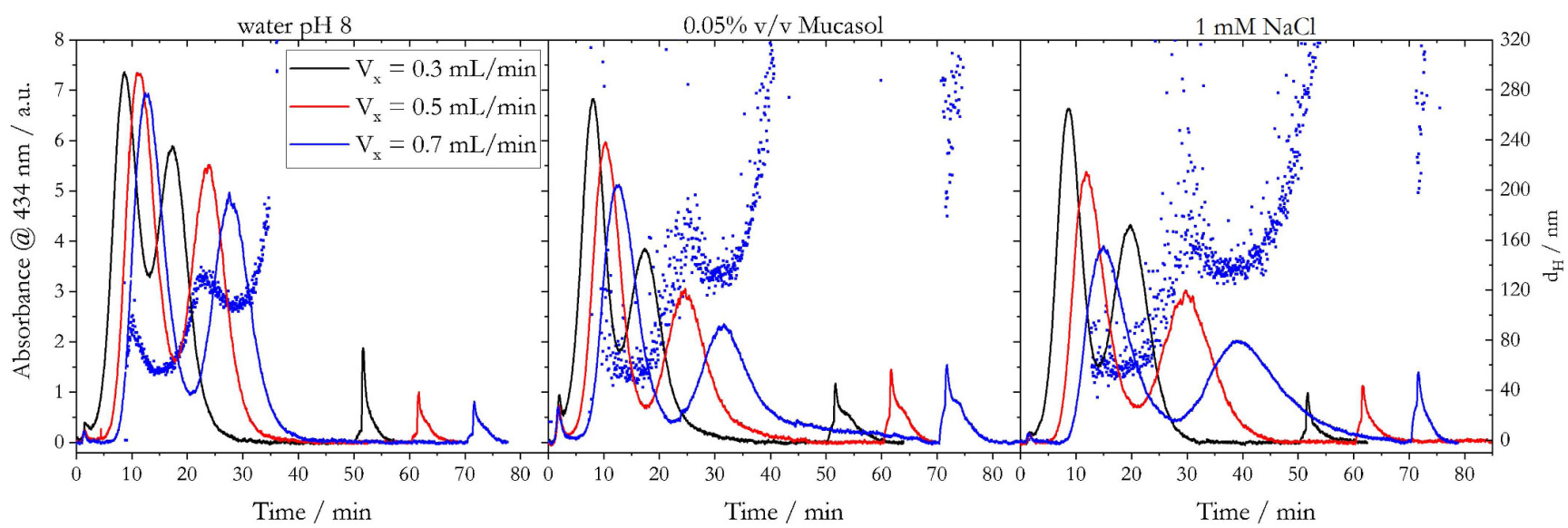

Fig. 7 Fractograms of a 1:1 mixture of 20- and 80-nm AgNP LA acquired with different cross-flows and carrier solutions. Hydrodynamic diameter was determined for $V_{x}=0.7 \mathrm{~mL} / \mathrm{min}$ 

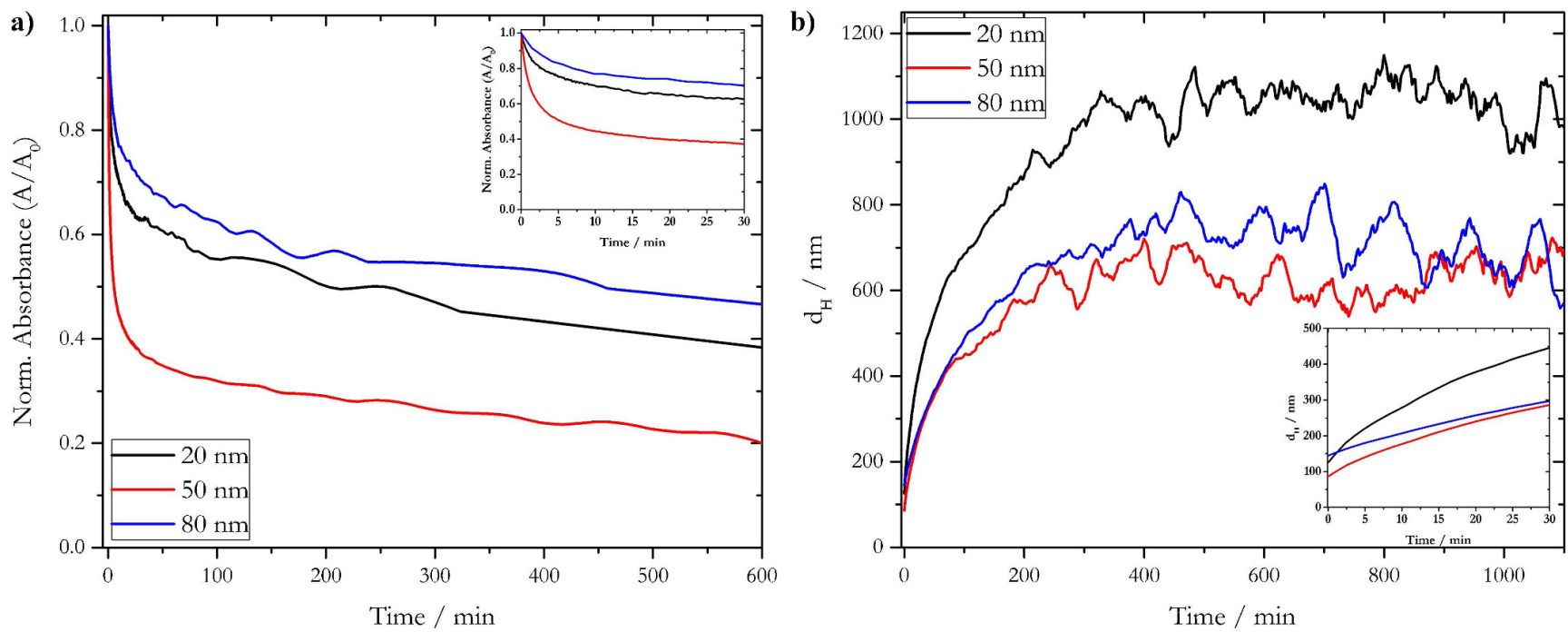

Fig. 8 Temporal trend of a the normalized absorbance of the SPR band (calculated by dividing the absorbance (A) at the given time after spiking AgNP LA into fjord water by the absorbance at $t=0 \mathrm{~min}(\mathrm{~A} 0)$ ) measured with $\mathrm{UV} / \mathrm{Vis}$ spectrophotometry and $\mathbf{b}$ hydrodynamic diameter measured with DLS

technique could be used to investigate the fate of AgNPs, in terms of their aggregation behavior, in natural waters. First, we characterized the behavior of AgNP_LA in the fjord water sample in batch using the DLS and UV/Vis techniques (Fig. 8). The size evolution over time was measured to check for possible NP aggregation during the AF4 experiments.

The normalized absorbance of the SPR band for 50-nm AgNP_LA featured the steepest decrease over time (red line, Fig. 8a), indicating a low stability compared to 20 - and $80-\mathrm{nm}$ AgNP_LA. Slowest decrease was observed for 80-nm AgNP_LA (for absorbance spectra, see Fig. S6a, b, c). This observation is in accordance with the determined zetapotentials (Table 2), where more negative values indicate enhanced stability. Normalized absorbance showed little change after ca. $10 \mathrm{~min}$ for all three AgNP_LA fractions (inset Fig. 8a). The original $d_{H}$ values (Table 2 ) were increased over time up to values around 600 and $1000 \mathrm{~nm}$ for $d_{H}=50 / 80$ and $20 \mathrm{~nm}$, respectively (for temporal trend of $P d I$, see Fig. S6d). The observed behavior is similar to that found with other electrostatically stabilized AgNPs in marine environments [20], and is attributed to the weak electrostatic stabilization provided by specific coatings such as the lactic acid, and potential interactions with the organic matter present in the sample. The observed transformations of the pristine AgNP_LA involved aggregation and possibly oxidation processes, though a detailed study of these phenomena is out of the scope of this manuscript. Using an analytical approach that combined AF4, ICP-MS, and UV/Vis, D.C. António et al. [75] showed that it is possible to assess in detail the agglomeration process of electrostatically stabilized AgNPs in artificial seawater.

As a case study of the AF4 technique optimization, a 1:1 mixture of 20- and 80-nm AgNP LA was spiked into ultrapure water and marine water collected from Kiel Fjord. The dispersion prepared in ultrapure water was directly injected into the AF4 system once prepared (black signal in Fig. 9). In order to track any changes in elution behavior/particle size with the change of the dispersion matrix, the AgNPs dispersed in marine water (red signal in Fig. 9) were injected into the AF4 system 20 min after the preparation, when small aggregates were already formed in the solution (Fig. 8). Based on the AF4 optimization experiments, $0.05 \% \mathrm{v} / \mathrm{v}$ Mucasol as carrier solution and $V_{x}=0.5 \mathrm{~mL} / \mathrm{min}$ were chosen for this case study as a compromise between separation quality and duration of the separation run.

A decrease in the elution peak height of ca. $66 \%$ was observed for both fractions, from 6.0 to 2.0 a.u. for $20-\mathrm{nm}$ AgNP_LA and from 3.8 to 1.3 a.u. for $80-n m$ AgNP_LA. This decrease was accompanied by a broadening of the 80 $\mathrm{nm}$ AgNP_LA elution peak and a shift to longer elution times, from $24 \mathrm{~min}$ with mixtures prepared in ultrapure water to about 28 min with AgNPs spiked in fjord water. In contrast, the $t_{R}$ for 20-nm AgNP_LA in fjord water decreased slightly (8.2 compared to 10.2 min for AgNP_LA dispersed in ultrapure water). In addition, an increase in the release peak was observed. This fact is explained by the formation of larger size particle fractions in high ionic strength matrices like the fjord water. Under cross-flow conditions, these aggregated fractions are completely retained in the separation channel and are released at the end of the elution process. DLS data showed poorly separated signals when AgNPs were spiked into natural fjord water, with an almost extinction of the 20nm AgNP_LA fraction, and a shift of the 80-nm AgNP_LA size fraction signal from 100 to $200 \mathrm{~nm}$, accompanied with much broader size distribution. In this case, a potential contribution from the dissolved organic matter in the fjord water should be also considered, thus limiting the applicability of this approach to similar matrices than those used in this study. 
Fig. 9 Fractograms and hydrodynamic diameter of a $1: 1$ mixture of 20-nm and 80-nm AgNP_LA acquired with $V_{x}=$ $0.5 \mathrm{~mL} / \mathrm{min}$ and $0.05 \% \mathrm{v} / \mathrm{v}$ Mucasol as carrier solution. Black color refers to a mixture prepared in ultrapure water; red color refers to the preparation in fjord water and injection into the AF4 system 20 min after preparation

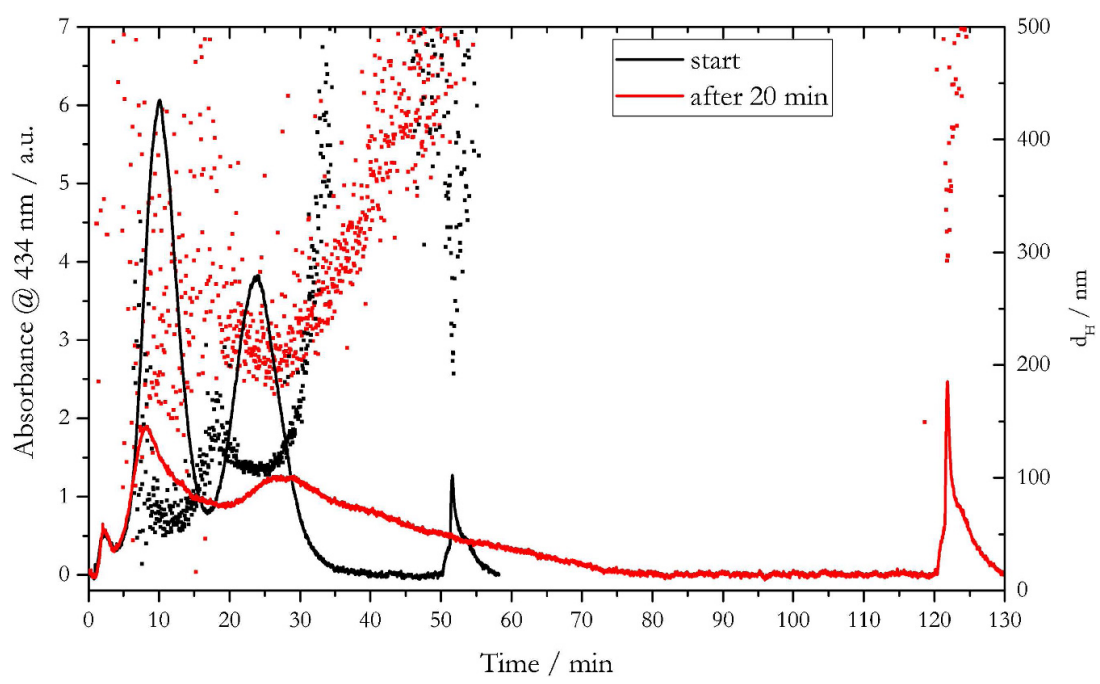

\section{Conclusions}

This study showed that AF4 coupled with a multiparameter detection system can be a powerful tool to investigate the behavior and fate of nanoparticles in natural waters. A thorough characterization and optimization of the system is required in order to determine the best possible conditions for a careful and reliable examination of AgNPs. It was shown that parameters such as quantity of injected particles, applied cross-flow, focusing time, and carrier solutions affect the nature of the acquired fractograms and thus the quality of the size separation of AgNPs. Furthermore, parameters for size separation have to be chosen in a manner that integrity of the AgNPs within the separation system will not be jeopardized in terms of particle-particle and particle-membrane interactions. However, a compromise has to be made between high sample throughput and separation quality, as best separation was achieved under high cross-flow conditions which came along with longer experiment times. Thus, the behavior and fate of AgNPs in natural waters, in terms of their aggregation kinetics, can be recorded using hyphenated AF4-UV/VisDLS, but at the cost of temporal resolution. The AF4 technique can be used for the direct injection of marine water samples to characterize stabilized silver nanoparticle species at concentrations exceeding those currently found in natural waters.

Supplementary Information The online version contains supplementary material available at https://doi.org/10.1007/s00216-021-03647-3.

Author contribution Conceptualization, F. Geißler and P. Lodeiro; experiments, F. Geißler and M. Martínez-Cabanas; formal analysis, F. Geißler and P. Lodeiro; writing (original draft preparation and editing), F. Geißler and M. Martínez-Cabanas; writing (review and editing), P. Lodeiro and E. Achterberg; supervision, P. Lodeiro and E. Achterberg. All the authors have read and agreed to the published version of the manuscript.
Funding Open Access funding enabled and organized by Projekt DEAL. This research was supported by a Marie Curie Intra European Fellowship within the 7th European Community Framework Programme (grant agreement number PIEF-GA-2012-329575) and the EU research project "ExPloTect-Ex-situ, near-real-time explosive compound detection in seawater" co-funded by the EMFF programme of the European Union [grant agreement number 863693]. P.L. is supported by a Beatriz Galindo Senior Fellowship (BG20/00104) from Ministerio de Ciencia, Innovación y Universidades of Spain, and University of Lleida. F.G. acknowledges the German Federal Ministry of Economic Affairs and Energy [OCEANSensor project; Funding Agreement 03SX459A] for funding.

Data availability The datasets generated during and/or analyzed during the current study are available from the corresponding authors on reasonable request.

\section{Declaration}

Conflict of interest The authors declare no competing interests.

Open Access This article is licensed under a Creative Commons Attribution 4.0 International License, which permits use, sharing, adaptation, distribution and reproduction in any medium or format, as long as you give appropriate credit to the original author(s) and the source, provide a link to the Creative Commons licence, and indicate if changes were made. The images or other third party material in this article are included in the article's Creative Commons licence, unless indicated otherwise in a credit line to the material. If material is not included in the article's Creative Commons licence and your intended use is not permitted by statutory regulation or exceeds the permitted use, you will need to obtain permission directly from the copyright holder. To view a copy of this licence, visit http://creativecommons.org/licenses/by/4.0/.

\section{References}

1. Turan NB, Erkan HS, Engin GO, Bilgili MS. Nanoparticles in the aquatic environment: usage, properties, transformation and toxicity — a review. Process Saf Environ Prot. 2019;130:238-49. 
2. Zhang Z, Shen W, Xue J, Liu Y, Liu Y, Yan P, et al. Recent advances in synthetic methods and applications of silver nanostructures. Nanoscale Res Lett. 2018;13:54.

3. Guo L, Jackman JA, Yang HH, Chen P, Cho NJ, Kim DH. Strategies for enhancing the sensitivity of plasmonic nanosensors. Nano Today. 2015;10(2):213-39.

4. Zeng J, Dong M, Zhu B, Chen D, Li Y. A new method towards the detection of DNA mutation by surface-enhanced Raman spectroscopy. Talanta. 2021;223:121746.

5. Lê QT, Ly NH, Kim MK, Lim SH, Son SJ, Zoh KD, et al. Nanostructured Raman substrates for the sensitive detection of submicrometer-sized plastic pollutants in water. J Hazard Mater. 2021;402:123499.

6. Ye Q, Zhao J, Huo F, Wang J, Cheng S, Kang T, et al. Nanosized $\mathrm{Ag} / \alpha-\mathrm{MnO} 2$ catalysts highly active for the low-temperature oxidation of carbon monoxide and benzene. Catal Today. 2011;175(1): 603-9.

7. Manno R, Sebastian V, Irusta S, Mallada R, Santamaria J. Ultrasmall silver nanoparticles immobilized in Mesoporous SBA-15. Microwave-assisted synthesis and catalytic activity in the 4nitrophenol reduction. Catal Today. 2021;362:81-9.

8. Jiang S, Wang L, Duan Y, An J, Luo Q, Zhang Y, et al. A novel strategy to construct supported silver nanocomposite as an ultrahigh efficient catalyst. Appl Catal B Environ. 2021;283:119592.

9. Liu H, Wu J, Fu Y, Wang B, Yang Q, Sharma GD, et al. One-step solution-processed low surface roughness silver nanowire composite transparent electrode for efficient flexible indium tin oxide-free polymer solar cells. Thin Solid Films. 2021;718:138486.

10. Tate J, Rogers JA, Jones CDW, Vyas B, Murphy DW, Li W, et al. Anodization and microcontact printing on electroless silver: solution-based fabrication procedures for low-voltage electronic systems with organic active components. Langmuir. 2000;16(14): 6054-60.

11. Lim GH, Kwon N, Han E, Bok S, Lee SE, Lim B. Flexible nanoporous silver membranes with unprecedented high effectiveness for electromagnetic interference shielding. J Ind Eng Chem. 2021;93:245-52.

12. Yu SJ, Yin YG, Liu JF. Silver nanoparticles in the environment. Environ Sci Process Impacts. 2013;15(1):78-92.

13. Tortella GR, Rubilar O, Diez MC, Padrão J, Zille A, Pieretti JC, et al. Advanced material against human (including COVID-19) and plant viruses: nanoparticles as a feasible strategy. Glob Challenges. 2020;2000049:1-13.

14. Sun RWY, Chen R, Chung NPY, Ho CM, Lin CLS, Che CM. Silver nanoparticles fabricated in HEPES buffer exhibit cytoprotective activities toward HIV-1 infected cells. Chem Commun. 2005;40:5059-61.

15. Klaine SJ, Alvarez PJJ, Batley GE, Fernandes TF, Handy RD, Lyon DY, et al. Nanomaterials in the environment: behavior, fate, bioavailability, and effects. Environ Toxicol Chem. 2008;27(9):182551.

16. Maurer-Jones MA, Gunsolus IL, Murphy CJ, Haynes CL. Toxicity of engineered nanoparticles in the environment. Anal Chem. 2013;85(6):3036-49.

17. Li L, Stoiber M, Wimmer A, Xu Z, Lindenblatt C, Helmreich B, et al. To what extent can full-scale wastewater treatment plant effluent influence the occurrence of silver-based nanoparticles in surface waters? Environ Sci Technol. 2016;50(12):6327-33.

18. Sanchís J, Jiménez-Lamana J, Abad E, Szpunar J, Farré M. Occurrence of cerium-, titanium-, and silver-bearing nanoparticles in the Besòs and Ebro Rivers. Environ Sci Technol. 2020;54(7): 3969-78.
19. Wimmer A, Urstoeger A, Funck NC, Adler FP, Lenz L, Doeblinger $\mathrm{M}$, et al. What happens to silver-based nanoparticles if they meet seawater? Water Res. 2020;171:115399.

20. Lodeiro P, Achterberg EP, Rey-Castro C, El-Shahawi MS. Effect of polymer coating composition on the aggregation rates of Ag nanoparticles in $\mathrm{NaCl}$ solutions and seawaters. Sci Total Environ. 2018:631-632:1153-62.

21. Lodeiro P, Browning TJ, Achterberg EP, Guillou A, El-Shahawi MS. Mechanisms of silver nanoparticle toxicity to the coastal marine diatom Chaetoceros curvisetus. Sci Rep. 2017;7(1):1-10.

22. Zhang L, Jiang H, Wang WX. Subcellular imaging of localization and transformation of silver nanoparticles in the oyster larvae. Environ Sci Technol. 2020;54(18):11434-42.

23. Myers MN. Overview of field-flow fractionation. J Microcolumn Sep. 1997;9(3):151-62.

24. Kowalkowski T, Buszewski B, Cantado C, Dondi F. Field-flow fractionation: theory, techniques, applications and the challenges. Crit Rev Anal Chem. 2006;36(2):129-35.

25. Giddings J. Field-flow fractionation: analysis of macromolecular, colloidal, and particulate materials. Science (80-). 1993;260:145665 .

26. Baalousha M, Stolpe B, Lead JR. Flow field-flow fractionation for the analysis and characterization of natural colloids and manufactured nanoparticles in environmental systems: a critical review. J Chromatogr A. 2011;1218(27):4078-103.

27. Cascio C, Gilliland D, Rossi F, Calzolai L, Contado C. Critical experimental evaluation of key methods to detect, size and quantify nanoparticulate silver. Anal Chem. 2014;86(24):12143-51.

28. Plüisch CS, Bössenecker B, Dobler L, Wittemann A. Zonal rotor centrifugation revisited: new horizons in sorting nanoparticles. RSC Adv. 2019;9(47):27549-59.

29. Konrath M, Gorenflo J, Hübner N, Nirschl H. Application of magnetic bearing technology in high-speed centrifugation. Chem Eng Sci. 2016;147:65-73.

30. Weinberg H, Galyean A, Leopold M. Evaluating engineered nanoparticles in natural waters. Trends Anal Chem. 2011;30(1):72-83.

31. Nischwitz V, Gottselig N, Braun M. Preparative field flow fractionation for complex environmental samples: online detection by inductively coupled plasma mass spectrometry and offline detection by gas chromatography with flame ionization. J Chromatogr A. 1632;2020:461581.

32. Sánchez-Cachero A, López-Sanz S, Fariñas NR, Ríos Á, del Rodríguez Martín-Doimeadios CR. A method based on asymmetric flow field flow fractionation hyphenated to inductively coupled plasma mass spectrometry for the monitoring of platinum nanoparticles in water samples. Talanta. 2021;222:1-8.

33. Wang Y, Cuss CW, Shotyk W. Application of asymmetric flow field-flow fractionation to the study of aquatic systems: coupled methods, challenges, and future needs. J Chromatogr A. 1632;2020:461600.

34. Giorgi F, Curran JM, Gilliland D, La Spina R, Whelan M, Patterson EA. Limitations of nanoparticles size characterization by asymmetric flow field-fractionation coupled with online dynamic light scattering. Chromatographia. 2021;84(2):199-206.

35. Battistini B, Petrucci F, Bocca B. In-house validation of AF4MALS-UV for polystyrene nanoplastic analysis. Anal Bioanal Chem. 2021:3027-39.

36. Li B, Chua SL, Ch'ng AL, Yu D, Koh SP, Phang H, et al. An effective approach for size characterization and mass quantification of silica nanoparticles in coffee creamer by AF4-ICP-MS. Anal Bioanal Chem. 2020;412(22):5499-512. 
37. Marassi V, Casolari S, Roda B, Zattoni A, Reschiglian P, Panzavolta S, et al. Hollow-fiber flow field-flow fractionation and multi-angle light scattering investigation of the size, shape and metal-release of silver nanoparticles in aqueous medium for nanorisk assessment. J Pharm Biomed Anal. 2015;106:92-9.

38. Marassi V, Roda B, Casolari S, Ortelli S, Blosi M, Zattoni A, et al. Hollow-fiber flow field-flow fractionation and multi-angle light scattering as a new analytical solution for quality control in pharmaceutical nanotechnology. Microchem J. 2018;136:149-56.

39. Marassi V, Di Cristo L, Smith SGJ, Ortelli S, Blosi M, Costa AL, et al. Silver nanoparticles as a medical device in healthcare settings: a five-step approach for candidate screening of coating agents. $\mathrm{R}$ Soc Open Sci. 2018;5(1):171113.

40. Baalousha M, Kammer FVD, Motelica-Heino M, Baborowski M, Hofmeister C, Le Coustumer P. Size-based speciation of natural colloidal particles by flow field flow fractionation, inductively coupled plasma-mass spectroscopy, and transmission electron microscopy/X-ray energy dispersive spectroscopy: colloids-trace element interaction. Environ Sci Technol. 2006;40(7):2156-62.

41. Baalousha M, Kammer FVD, Motelica-Heino M, Le Coustumer P. 3D characterization of natural colloids by FIFFF-MALLS-TEM. Anal Bioanal Chem. 2005;383(4):549-56.

42. Kammer FVD, Baborowski M, Friese K. Field-flow fractionation coupled to multi-angle laser light scattering detectors: applicability and analytical benefits for the analysis of environmental colloids. Anal Chim Acta. 2005;552(1-2):166-74

43. Stolpe B, Zhou Z, Guo L, Shiller AM. Colloidal size distribution of humic- and protein-like fluorescent organic matter in the northern Gulf of Mexico. Mar Chem. 2014;164:25-37.

44. Stolpe B, Guo L, Shiller AM, Hassellöv M. Size and composition of colloidal organic matter and trace elements in the Mississippi River, Pearl River and the northern Gulf of Mexico, as characterized by flow field-flow fractionation. Mar Chem. 2010;118(3-4): 119-28.

45. Amde M, Tan ZQ, Liu J. Separation and size characterization of zinc oxide nanoparticles in environmental waters using asymmetrical flow field-flow fractionation. Talanta. 2019;200:357-65.

46. Kim ST, Cho HR, Jung EC, Cha W, Baik MH, Lee S. Asymmetrical flow field-flow fractionation coupled with a liquid waveguide capillary cell for monitoring natural colloids in groundwater. Appl Geochem. 2017;87:102-7.

47. Loosli F, Wang J, Sikder M, Afshinnia K, Baalousha M. Analysis of engineered nanomaterials ( $\mathrm{Ag}, \mathrm{CeO} 2$ and $\mathrm{Fe} 2 \mathrm{O} 3$ ) in spiked surface waters at environmentally relevant particle concentrations. Sci Total Environ. 2020;715:136927.

48. Loosli F, Yi Z, Wang J, Baalousha M. Dispersion of natural nanomaterials in surface waters for better characterization of their physicochemical properties by AF4-ICP-MS-TEM. Sci Total Environ. 2019;682:663-72.

49. Jang MH, Lee S, Hwang YS. Characterization of silver nanoparticles under environmentally relevant conditions using asymmetrical flow field-flow fractionation (AF4). PLoS One. 2015;10(11): e0143149.

50. Furtado LM, Hoque ME, Mitrano DF, Ranville JF, Cheever B, Frost PC, et al. The persistence and transformation of silver nanoparticles in littoral lake mesocosms monitored using various analytical techniques. Environ Chem. 2014;11(4):419-30.

51. Jie CY, Hsin SY, Su CH, Ho HC. Comparison of three analytical methods to measure the size of silver nanoparticles in real environmental water and wastewater samples. J Hazard Mater. 2017;322: 95-104.
52. Boughbina-Portolés A, Sanjuan-Navarro L, Moliner-Martínez Y, Campíns-Falcó P. Study of the stability of citrate capped agnps in several environmental water matrices by asymmetrical flow field flow fractionation. Nanomaterials. 2021;11(4):926.

53. Lowry GV, Hill RJ, Harper S, Rawle AF, Hendren CO, Klaessig F, et al. Guidance to improve the scientific value of zeta-potential measurements in nanoEHS. Environ Sci Nano. 2016;3(5):953-65.

54. Hubbard A Interface science and technology. In: Theory of colloid and interfacial electric phenomena. Elsevier; 2006.

55. Lodeiro P, Achterberg EP, Pampín J, Affatati A, El-Shahawi MS Silver nanoparticles coated with natural polysaccharides as models to study AgNP aggregation kinetics using UV-visible spectrophotometry upon discharge in complex environments. Sci Total Environ. 2016;539:7-16.

56. Verwey EJW, Overbeek JTG, van Nes K. Theory of the stability of lyophobic colloids: the interaction of sol particles having an electric double layer. Amsterdam: Elsevier Publishing Company; 1948.

57. Derjaguin B, Landau L. Theory of the stability of strongly charged lyophobic sols and of the adhesion of strongly charged particles in solutions of electrolytes. Prog Surf Sci. 1993;43(1):30-59.

58. Stewart ME, Anderton CR, Thompson LB, Maria J, Gray SK, Rogers JA, et al. Nanostructured plasmonic sensors. Chem Rev. 2008;108(2):494-521.

59. Gigault J, Pettibone JM, Schmitt C, Hackley VA. Rational strategy for characterization of nanoscale particles by asymmetric-flow field flow fractionation: a tutorial. Anal Chim Acta. 2014;809:9-24.

60. Wahlund K-G. Flow field-flow fractionation: critical overview. J Chromatogr A. 2013;1287:97-112.

61. Benincasa MA, Giddings JC. Separation and molecular weight distribution of anionic and cationic water-soluble polymers by flow field-flow fractionation. Anal Chem. 1992;64(7):790-8.

62. Arfvidsson C, Wahlund KG. Mass overloading in the flow fieldflow fractionation channel studied by the behaviour of the ultralarge wheat protein glutenin. J Chromatogr A. 2003;1011(1-2): 99-109.

63. Hagendorfer H, Kaegi R, Parlinska M, Sinnet B, Ludwig C, Ulrich A. Characterization of silver nanoparticle products using asymmetric flow field flow fractionation with a multidetector approach - a comparison to transmission electron microscopy and batch dynamic light scattering. Anal Chem. 2012;84(6):2678-85.

64. Roda B, Cioffi N, Ditaranto N, Zattoni A, Casolari S, Melucci D, et al. Biocompatible channels for field-flow fractionation of biological samples: correlation between surface composition and operating performance. Anal Bioanal Chem. 2005;381(3):639-46.

65. Reschiglian P, Melucci D, Torsi G. Experimental study on the retention of silica particles in gravitational field-flow fractionation. Effects of the mobile phase composition. J Chromatogr A. 1996;740(2):245-52.

66. Stephen Williams P, Xu Y, Reschiglian P, Calvin GJ. Colloid characterization by sedimentation field-flow fractionation: correction for particle - wall interaction. Anal Chem. 1997;69(3):349-60.

67. Susanto H, Ulbricht M. Characteristics, performance and stability of polyethersulfone ultrafiltration membranes prepared by phase separation method using different macromolecular additives. J Membr Sci. 2009;327(1-2):125-35.

68. El Badawy AM, Luxton TP, Silva RG, Scheckel KG, Suidan MT, Tolaymat TM. Impact of environmental conditions $(\mathrm{pH}$, ionic strength, and electrolyte type) on the surface charge and aggregation of silver nanoparticles suspensions. Environ Sci Technol. 2010;44(4):1260-6. 
69. Moon MH, Hwang I. Hydrodynamic vs. focusing relaxation in asymmetrical flow field-flow fractionation. J Liq Chromatogr Relat Technol. 2001;24(20):3069-83.

70. Wahlund KG, Giddings JC. Properties of an asymmetrical flow field-flow fractionation channel having one permeable wall. Anal Chem. 1987;59(9):1332-9.

71. Schimpf ME, Wahlund KG. Asymmetrical flow field-flow fractionation as a method to study the behavior of humic acids in solution. $\mathrm{J}$ Microcolumn Sep. 1997;9(7):535-43.

72. Hartmann RL, Williams SKR. Flow field-flow fractionation as an analytical technique to rapidly quantitate membrane fouling. J Membr Sci. 2002;209(1):93-106.

73. Giddings JC, Caldwell KD. Field-flow fractionation: choices in programmed and nonprogrammed operation. Anal Chem. 1984;56(12):2093-9.
74. Dubascoux S, Von Der Kammer F, Le Hécho I, Gautier MP, Lespes G. Optimisation of asymmetrical flow field flow fractionation for environmental nanoparticles separation. J Chromatogr A. 2008;1206(2):160-5.

75. António DC, Cascio C, Jakšić Ž, Jurašin D, Lyons DM, Nogueira AJA, et al. Assessing silver nanoparticles behaviour in artificial seawater by mean of AF4 and spICP-MS. Mar Environ Res. 2015;111:162-9.

Publisher's note Springer Nature remains neutral with regard to jurisdictional claims in published maps and institutional affiliations. 